\title{
Transcriptomic Analyses of Camellia oleifera 'Huaxin' Leaf Reveal Candidate Genes Related to Long-Term Cold Stress
}

\author{
Lingli Wu ${ }^{1,2}$, Jian'an $\mathrm{Li}^{1,2, *}$, Ze Li ${ }^{1,2}{ }^{-1}$, Fanhang Zhang ${ }^{1,2}$ and Xiaofeng Tan ${ }^{1,2, *}$ \\ 1 Key Laboratory of Cultivation and Protection for Non-wood Forest Trees of Ministry of Education and the \\ Key Laboratory of Non-Wood Forest Products of Forestry Ministry, Central South University of Forestry and \\ Technology, Changsha 410004, China; wulingli0307@163.com (L.W.); lize1853@163.com (Z.L.); \\ ZhangFH1013@163.com (F.Z.) \\ 2 Engineering Technology Research Center of Southern Hilly and Mountainous Ecological Non-Wood Forest \\ Industry of Hunan Province, Changsha 410004, China \\ * Correspondence: lja0731@126.com (J.L.); tanxiaofengcn@126.com (X.T.)
}

Received: 8 November 2019; Accepted: 22 January 2020; Published: 28 January 2020

\begin{abstract}
Huaxin' is a new high-yielding timber cultivar of Camellia oleifera of high economic value, and has been widely cultivated in the red soil hilly region of Hunan Province of the People's Republic of China in recent years. However, its quality and production are severely affected by low temperatures during flowering. To find genes related to cold tolerance and further explore new candidategenes for chilling-tolerance, Illumina NGS (Next Generation Sequencing) technology was used to perform transcriptomic analyses of C. oleifera 'Huaxin' leaves under long-term cold stress. Nine cDNA libraries were sequenced, and $58.31 \mathrm{~Gb}$ high-quality clean reads were obtained with an average of $5.92 \mathrm{~Gb}$ reads for each sample. A total of 191,150 transcripts were obtained after assembly. Among them, 100,703 unigenes were generated, and 44,610 unigenes were annotated. In total, 1564 differentially expressed genes (DEGs) were identified both in the A_B and A_C gene sets. In the current study, Gene Ontology (GO) and Kyoto Encyclopedia of Genes and Genomes (KEGG) pathway enrichment analyses were performed, andrevealed a group of cold-responsive genes related to hormone regulation, photosynthesis, membrane systems, and osmoregulation; these genes encoded many key proteins in plant biological processes, such as serine/threonine-protein kinase (STPK), transcription factors (TFs), fatty acid desaturase (FAD), lipid-transfer proteins (LTPs), soluble sugars synthetases, and flavonoid biosynthetic enzymes. Some physiological indicators of $C$. oleifera 'Huaxin' were determined under three temperature conditions, and the results were consistent with the molecular sequencing. In addition, the expression levels of 12 DEGs were verified using quantitative real-time polymerase chain reaction (qRT-PCR). In summary, the results of DEGs analysis together with qRT-PCR tests contribute to the understanding of cold tolerance and further exploring new candidate genes for chilling-tolerance in molecular breeding programs of C. oleifera 'Huaxin'.
\end{abstract}

Keywords: Camellia oleifera; long-term cold stress; transcriptome sequence; DEGs

\section{Introduction}

Camellia oleifera Abel. is a member of the genus Camellia in the family Theaceae. In China, cultivated C. oleifera is one of the four major woody oil species, followed by the tung tree (Vernicia fordii Hemsley), walnut (Juglansregia), and Chinese tallow tree (Sapium sebiferum) [1,2]. The tea oil extracted from C. oleifera seeds is an edible oil known as "eastern olive oil," because of its high nutritional value and health benefits [3]. Tea oil has a similar chemical composition to that of olive oil; both contain high amounts of unsaturated fatty acids [4]. As an evergreen broadleaf shrub or small tree, C. oleifera is 
widely distributed in the subtropical mountainous areas of the Yangtze River basin and South China [5]. The Jiangxi, Hunan, and Guangxi provinces are the main habitat areas, accounting for $76 \%$ of the total area of production in the country [6]. With the rapid development of the C. oleifera industry, large areas of red soil hilly region of southern China have been planted with $C$. oleifera in recent years.

Hunan has a subtropical monsoon humid climate with four distinct seasons, where the mean air temperature in autumn and winter is $10-12{ }^{\circ} \mathrm{C}$, and the mean January air temperature is $4-8{ }^{\circ} \mathrm{C}$. C. oleifera blossoms at daily average temperatures ranging from 10 to $20^{\circ} \mathrm{C}$, and $8-14{ }^{\circ} \mathrm{C}$ is the optimum temperature range for flowering [7]. Unlike most of the woody plants in China, which usually bloom in spring (from March to May in the same year), C. oleifera usually flowers from November of that year to January of the next year. Hence, damage due to low temperature stress at the flowering phase has severely hindered oil production of $C$. oleifera in the hilly red soil region of southern China.

Temperature, a very important ecological factor for plant growth, affects the distribution, productivity, and survivability of plants [8]. Previous studies have confirmed that the expansion of tea plant (Camellia sinensis) cultivation has been restricted due to temperature, and cold stress might cause the fall of flowers and fruits, leading to a reduced yield $[9,10]$. Furthermore, physiological and phenotypic changes occur in response to low-temperature stress, such as decreased chlorophyll content, photosynthetic rate, and electron transport rate (ETR) [11]. Tropical or subtropical plants subjected to air temperatures less than $10^{\circ} \mathrm{C}$ are easily affected by chilling stress [12]. Cold and freezing weather would cause a large number of flower and fruit to fall, and it is also not conducive to pollination and young fruit formation because pollen cracking is inhibited when the temperature drops below $8^{\circ} \mathrm{C}$ [7]. Woody plants in temperate climates achieve their cold tolerance ability to survive cold stress through a series of processes induced by seasonal acclimation to low temperatures, known as cold acclimation [13]. Cold acclimation triggers various adaptive molecular mechanisms in response to long-term cold stress [14], such as protection and stabilization of cellular membranes, enhancement of antioxidant mechanisms, synthesis and accumulation of osmotic protective substances, and unique cryoprotective proteins [15]. There is a positive correlation between the accumulated temperature at the flowering stage and the yield of C. oleifera [16].

In 1977, a C. oleifera research team found a wild tea-oil tree with good fruit performance and strong resistance to disease in Chaling County, Hunan Province. From 1978 to 2009, through comparison and regional testing of $84 \mathrm{C}$. oleifera clones with good characters, the clones with the best comprehensive characters were screened out, and named 'Huaxin' by the forest variety Committee of the State Forestry Administration. 'Huaxin' is a new C. oleifera cultivar, which has high and stable yields, strong disease-resistant ability, and precocity [17]. Because of its high yield and good economic returns, it has been widely cultivated in the red soil hilly region of Hunan Province in recent years. However, $C$. oleifera usually flowers in autumn and winter, and it is easily affected by cold temperatures during flowering [18]. Previous studies showed that low temperature inhibited the normal opening of 'Huaxin' flower buds, and an appropriate temperature was favorable for the growth of young fruits [19]. To improve its cold resistance and extend its cultivation to colder areas in the north, it is necessary to identify the candidate genes related to long-term cold stress and understand the regulation of gene expression of C. oleifera 'Huaxin' during flowering. This improved understanding also provides a basis for cultivar improvement and molecular breeding of C. oleifera.

Approximately 120 species belong to the genus Camellia, and C. oleifera and C. sinensis are the two most representative species, with high economic value [5]. However, the completely sequenced genome for these species remains unavailable. For non-model plant species that lack gene information, transcriptome sequencing is an alternative rapid approach for studying the molecular mechanisms of physiological processes. Although several transcriptomic analyses in tea plants (C. sinensis) have been reported [20-22], a few transcriptomic studies of $C$. oleifera have been undertaken. In one study, the transcriptome of $C$. oleifera 'Huaxin' was sequenced and de novo assembled using different plant tissues, which revealed some candidate genes associated with lipid metabolism [23]. Though atranscriptome profile of wild oil-tea camellia from various latitudes and elevations under low 
environmental temperatures in winter has been reported [5], transcriptomic studies of cultivated $C$. oleifera 'Huaxin' under controllable temperature conditions are few at present.

A previous study has shown that low temperature had a great influence on the phenotype and physiology of C. oleifera 'Huaxin' leaves [19]. To explore the mechanism of C. oleifera 'Huaxin' leaves in response to long-term cold stress, a fully characterized C. oleifera 'Huaxin' transcriptome using Illumina NGS technology combining with physiological experiments was performed. This led to the discovery of several differentially expressed genes (DEGs) in response to cold and, ultimately, to a better understanding of the molecular mechanisms involved in the C. oleifera 'Huaxin' adaptation to low temperatures. Some candidate genes related to cold acclimation were identified that provide a basis for cultivar improvement and further molecular breeding of C. oleifera.

\section{Results}

\subsection{Morphological Observation and Physiological Indexes of C. oleifera 'Huaxin' Under Three Temperatures}

There were substantial differences in leaf color among three temperature treatments. The leaves of C. oleifera 'Huaxin' were thick and dark green under treatment $A$, but turned yellow at the edges under treatment $B$, and were slightly pale under treatment $C$ (Figure 1a-c). In addition, the chlorophyll contents $(\mathrm{Chl})$, net photosynthetic rate $\left(P_{n}\right)$, and electron transfer rate (ETR) were significantly different under three treatments; all values were the lowest for treatment $B$, followed by treatment $C$, and the value of treatment $A$ was the highest (Figure $1 \mathrm{~d}-\mathrm{f}$ ). However, the soluble sugar contents of $C$. oleifera 'Huaxin' under treatments B and $\mathrm{C}$ were significantly higher compared with treatment $\mathrm{A}$, at $41.67 \%$ and $33.33 \%$ higher, respectively (Figure 1g). The starch content of C. oleifera 'Huaxin' under treatment $\mathrm{A}$ was the highest among the treatments, at $85.67 \%$ and $24.73 \%$ higher than treatments $\mathrm{B}$ and $\mathrm{C}$, respectively (Figure 1h). The relative water content (RWC) of treatment B was the lowest. Compared to treatment A, RWC of treatment B was significantly decreased by $11.69 \%$; however, no significant differences were found between treatments $A$ and $C$ (Figure 1i). The galactose content of C. oleifera 'Huaxin' under treatment B was the highest among the treatments, at $42.56 \%$ and $26.36 \%$ higher than treatments A and C, respectively (Figure S2).

\subsection{Transcriptome Sequencing and Assembly}

An overview of the RNA-Seq reads derived from nine cDNA libraries (A1, A2, A3, B1, B2, B3, $\mathrm{C} 1, \mathrm{C} 2$, and C3) are shown in Additional File 1: Table S1. After quality control, $58.31 \mathrm{~Gb}$ high-quality clean reads were obtained with an average of $5.92 \mathrm{~Gb}$ reads for each sample, and the percentage of Q30 base in each sample was $>92.56 \%$. The proportion of mapped reads per library ranged from $70.43 \%$ to $74.59 \%$. A total of 191,150 transcripts were obtained from the clean reads with an N50 length of 1690 $\mathrm{bp}$ and a mean length of $1034.37 \mathrm{bp}$. Among them, 100,703 unigenes were generated, and the average length of the unigenes was $790.43 \mathrm{bp}$. There were $64,762(64.31 \%)$ unigenes with a length $>300 \mathrm{bp}$, while the lengths of $23,846(23.68 \%)$ unigenes were $>1000 \mathrm{bp}$. The length distributions of the transcripts and unigenes are listed in Table 1 . The assembly quality of the transcriptome was rated as satisfactory.

Table 1. Length distribution of the transcripts and unigenes clustered from de novo assembly.

\begin{tabular}{ccc}
\hline Length Range & Transcript & Unigene \\
\hline $200-300$ & $42,879(22.43 \%)$ & $35,944(35.69 \%)$ \\
$300-500$ & $35,226(18.43 \%)$ & $21,988(21.83 \%)$ \\
$500-1000$ & $43,723(22.87 \%)$ & $18,930(18.80 \%)$ \\
$1000-2000$ & $42,472(22.22 \%)$ & $14,590(14.49 \%)$ \\
$2000+$ & $26,850(14.05 \%)$ & $9251(9.19 \%)$ \\
Total number & 191,150 & 100,703 \\
Total length & $197,720,185$ & $79,598,970$ \\
N50 length & 1690 & 1413 \\
Mean length & 1034.37 & 790.43 \\
\hline
\end{tabular}




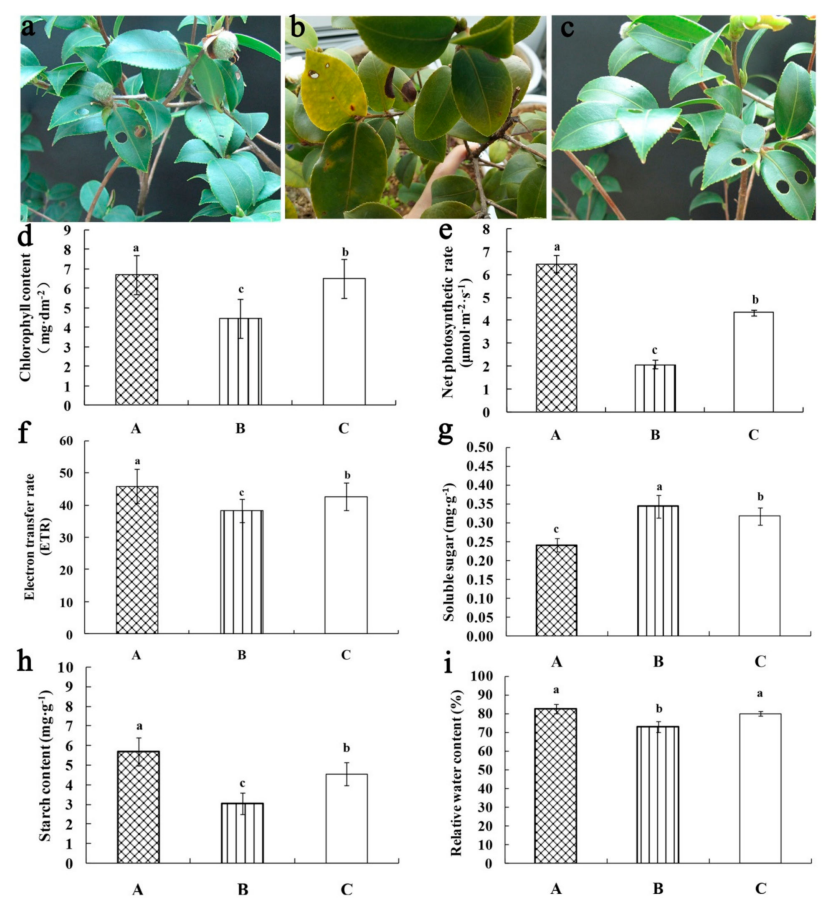

Figure 1. Effect of different temperaturetreatments on phenotypic changes, chlorophyll contents, net photosynthetic rate $\left(P_{n}\right)$, electron transfer rate (ETR), soluble sugar, starch content, and relative water contentin Camelliaoleifera ${ }^{\prime}$ Huanxin' leaves. (a) $25^{\circ} \mathrm{C}$; (b) $6{ }^{\circ} \mathrm{C}$; (c) Low environmental temperature; (d) Chlorophyll content; (e) Net photosynthetic rate; (f) Electron transfer rate; (g) Soluble sugar content; (h) Starch content; (i) Relative water content. Data represent the mean \pm SE $(n=3)$. Lowercase letters indicate significant differences among different temperature treatments at $p \leq 0.05$ according to Duncan's multiple range test (DMRT).

\subsection{Gene Annotation and Functional Classification}

BLAST was used for unigene function annotation with common functional databases such as NCBI non-redundant protein sequences (NR), a manually annotated and reviewed protein sequence database (Swiss-prot), Gene Ontology (GO), Clusters of Genes (COG), EuKaryotic Orthologous Groups (KOG), the Kyoto Encyclopedia of Genes and Genomes (KEGG), eggNOG, and Protein family (Pfam). Out of the 100,703, 44,610 (44.30\%) were successfully matched to homologous sequences in at least one of the databases mentioned above. Among them, 13,161 (29.50\%), 28,213 (63.24\%), 14,824 (33.23\%), 23,416 (52.49\%), 26,264 (58.87\%), 24,203 (54.25\%), 40,098 (89.89\%), and 43,518 (97.55\%) annotated unigenes were obtained from the COG, GO, KEGG, KOG, Pfam, Swiss-Prot, eggnog, and NR databases, respectively (Table 2).

Table 2. Unigene function annotation statistics of Camellia oleifera 'Huaxin' transcriptome. COG: Clusters of Genes; GO: Gene Ontology; KEGG: Kyoto Encyclopedia of Genes and Genomes; Pfam: Protein family; KOG: EuKaryotic Orthologous Groups; NR: NCBI non-redundant protein sequences.

\begin{tabular}{llll}
\hline Annotated Databases & Annotated Number & Length $<=\mathbf{3 0 0}$ bp & Length $>=\mathbf{1 0 0 0}$ bp \\
\hline COG & 13,161 & 3273 & 7010 \\
GO & 28,213 & 9019 & 12,485 \\
KEGG & 14,824 & 4606 & 7355 \\
KOG & 23,416 & 7249 & 11,409 \\
Pfam & 26,264 & 7364 & 14,330 \\
Swiss-Prot & 24,203 & 7277 & 13,150 \\
eggNOG & 40,098 & 13,082 & 17,864 \\
NR & 43,518 & 14,758 & 18,596 \\
All & 44,610 & 14,946 & 18,668 \\
\hline
\end{tabular}


The NR database produced the largest number of annotations with a total of 43,518 unigenes. Based on the results of the smallest Blast E value, C. oleifera 'Huaxin' showed the most matches to Vitis vinifera (12.14\%), followed by Quercus suber (4.71\%), and Juglans regia (2.36\%) (Figure 2a). The GO is an international standardized classification system of gene functions. It provides a dynamically updated standard vocabulary to fully describe the possible molecular functions of gene products, the cellular environment, and the biological processes. A total of 28,213 unigenes were annotated and classified into 58 GO pathways (Figure 2b) in three categories involving Cell Component (CC), Molecular Function (MF), and Biological Processes (BP). The top three GO terms for the CC category were 'cell' (44.78\%), 'cell part' (44.76\%), and 'membrane' (36.49\%); for the MF category 'catalytic activity' (51.81\%) ranked the first, followed by 'binding' (47.57\%) and 'transporter activity' (7.43\%); for the BP category, the top three GO terms were 'metabolic process' (52.54\%), 'cellular process' (48.50\%) and 'single-organism process' (33.13\%). In addition, genes were also highly represented in three GO terms including 'organelle,' 'response to stimulus', and 'biological regulation'. The KOG classifications were based on genetic orthologous and evolutionary relationships. In total, 23,416 unigenes were grouped into 25 functional classifications based on the KOG database (Figure 2c). Among these classifications, the 'general function prediction only' $(26.18 \%)$ ranked highest, followed by 'posttranslational modification, protein turnover, chaperones' (10.15\%), 'signal transduction mechanisms' $(9.17 \%)$, 'translation, ribosomal structure and biogenesis' (6.10\%), 'energy production and conversion' (5.88\%), 'carbohydrate transport and metabolism' (5.77\%), 'transcription' (5\%), and 'intracellular trafficking, secretion, and vesicular transport' $(4.98 \%)$.

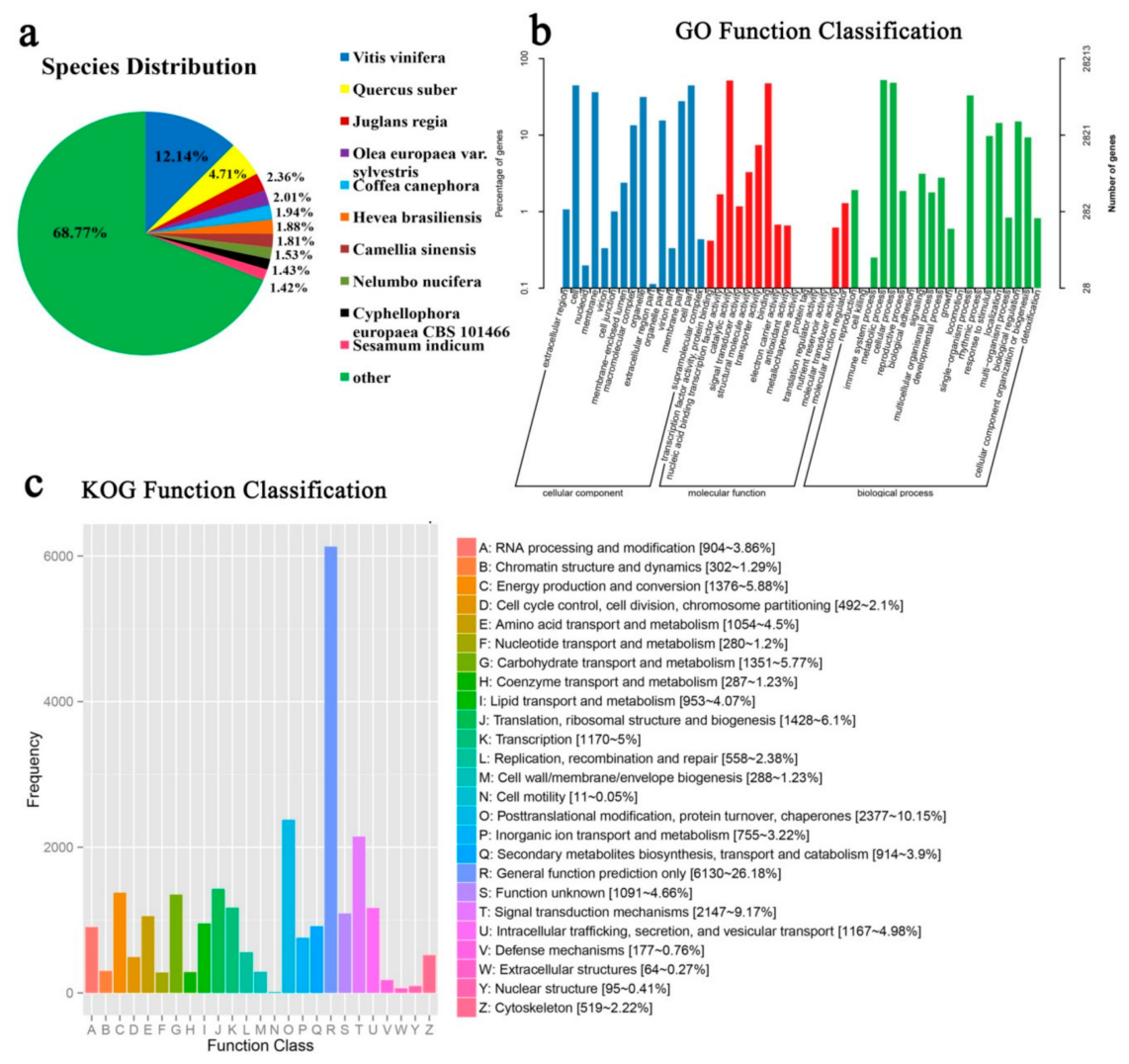

Figure 2. Functional annotations of the assembled transcriptome. (a) NR annotated species distribution map similar to the Camellia oleifera 'Huaxin' transcriptome; (b) GO classification of the annotated unigenes; (c) KOG function classification of the consensus sequence. 


\subsection{Comparative Analyses of Differentially Expressed Genes (DEGs)}

DEGs were analyzed using the reads per kilo base per million (RPKM) method to determine the degree of overlap among the three sample groups. Venn diagrams were used to summarize the number of DEGs among the differential expression gene sets (DEGs sets), including A_B, A_C, and B_C. The total number of DEGs identified between group A and group B was 2641, including 1169 up-regulated and 1472 down-regulated genes, while the total number of DEGs between group A and group C was 3566, including 2160 up-regulated and 1406 down-regulated genes, and the total number of DEGs between group B and group C was 1098, including 851 up-regulated and 247 down-regulated genes (Figure 3a). Moreover, 159 DEGs (90 commonly up-regulated and 10 commonly down-regulated) were shared among the three DEG sets (Figure $3 b-d)$.
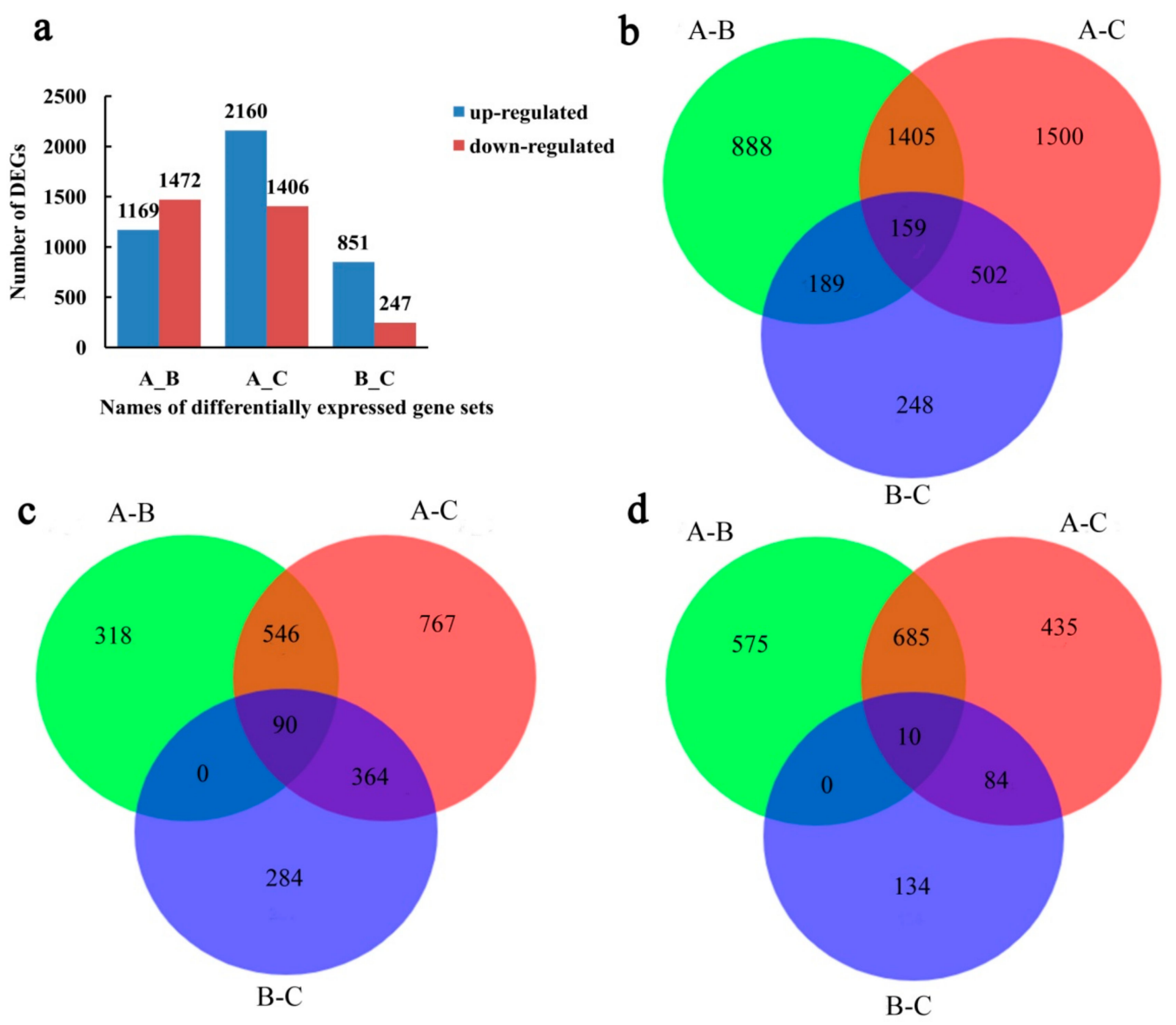

Figure 3. The graphical representation of differentially expressed genes (DEGs) of Camellia oleifera 'Huaxin' in response to low-temperature stress. (a) Number of up/down-regulated DEGs in the A_B, A_C, and B_C differential expression gene sets; (b) Venn diagram showing all DEGs numbers among the three gene sets; (c) Venn diagram showing up-regulated genes DEGs numbers among the three gene sets; (d) Venn diagram showing down-regulated DEGs numbers among the three gene sets.

\subsection{Enriched KEGG Pathway Analyses of DEGs in Response to Low Temperature}

KEGG is a signal pathway database for the systematic analyses of metabolic pathways and the functions of gene products in cells. The significance of enrichment was calculated by Fisher test, and enrichment of DEGs was analyzed at a significance level of $p<0.05$ with an extremely rich signal pathway map. In the A_B gene set, 411 DEGs were assigned to the KEGG database involved in 110 pathways; in the A_C gene set, 627 DEGs were assigned to 117 pathways; and in the B_C gene set, 228 DEGs were assigned to 89 pathways. The 10 most reliable and significantly enriched 
pathways of DEGs in the three DEG sets are listed in Table 3. The enrichment degree of pathway was analyzed by enrichment factor. On integrating the numbers of differentially expressed genes in the A_B and A_C gene sets, seven major pathways related to cold acclimation mechanism were obtained (Additional File 2: Figure S1). They were 'Photosynthesis-antenna proteins (KO 00196)','Photosynthesis (KO 00195)','Phenylalanine metabolism (KO 00360)','Plant hormone signal transduction (KO 04075)', 'Galactose metabolism (KO 00052)', 'Phenylpropanoid biosynthesis (KO 00940)', and 'Starch and sucrose metabolism (KO 00500)'. As shown in Table 4, for the 'Starch and sucrose metabolism' and 'Plant hormone signal transduction' pathways, the number of DEGs in A_C was higher than in the A_B or B_C gene sets, but for the biological metabolism and synthesis pathways, there were no differences in the number of DEGs between the A_B and A_C gene sets.

Table 3. The most reliable top ten significantly enriched pathways of DEGs in the three differential expression gene sets.

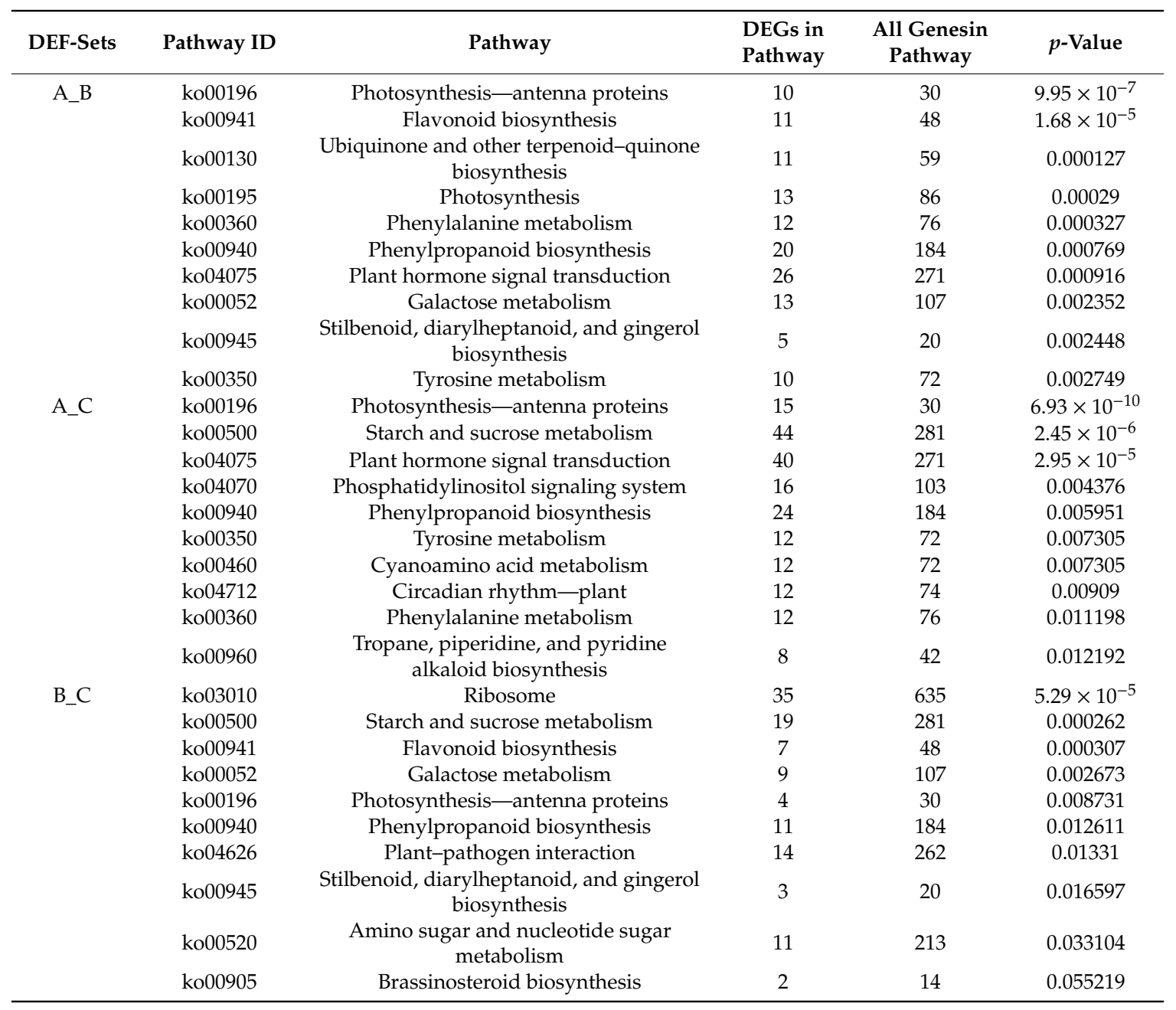

Table 4. DEG statistics in seven major pathways of Camellia oleifera 'Huaxin'.

\begin{tabular}{lllll}
\hline Pathway & Pathway ID & A_B & A_C & B_C \\
\hline Photosynthesis-antenna proteins & ko 00196 & 10 & 15 & 4 \\
Photosynthesis & ko 00195 & 13 & 11 & 2 \\
Phenylalanine metabolism & ko 00360 & 12 & 12 & 5 \\
Plant hormone signal transduction & ko 04075 & 26 & 40 & 11 \\
Galactose metabolism & ko 00052 & 13 & 13 & 9 \\
Phenylpropanoid biosynthesis & ko00940 & 20 & 24 & 11 \\
Starch and sucrose metabolism & ko 00500 & 23 & 44 & 19 \\
\hline
\end{tabular}




\subsection{TFs and PK Responding to Low Temperature}

The gene expression network regulated by TFs plays an important role in the growth and development of plants. In this study, a total of 125 (64 up- and 61 down-regulated) and 184 (120 upand 64 down-regulated) transcription factor genes (TFs) were identified in the A_B and A_C gene sets, respectively (Additional File 3: Tables S2 and S3). The key TF families involved in cold acclimation were AP2, Myb, WRKY, bHLH, Hlh, zinc finger, B3, LOB, bZIP, GRAS, and NAC. In gene set A_B, the Myb family was the largest group (16\%), followed by the AP2 family $(12 \%)$ and the NAC family $(8.8 \%)$ (Figure 4a). In A_C gene set, the top three families were zinc finger (16.3\%), Myb (13.04\%), and AP2 $(9.78 \%)$ (Figure $4 \mathrm{~b})$. The current study measured the differential expression of TFs by cluster analyses and identified $18 \mathrm{TFs}$ that showed significant differences among different samples treated at different temperatures (Figure 4c, Additional File 3: Table S4). The heat map of TFs showed that significantly up-regulated genes included two TFs members belonging to the NAC family (NAC2 and NAC29), two TFs-from the WRKY family (WRKY31and WRKY75), two TFs from the MYB family (MYB2 and MYB8), and two TFs from the zinc finger family (zinc finger2 and zinc finger3), identified in groups $\mathrm{B}$ and $\mathrm{C}$ (treated at $6{ }^{\circ} \mathrm{C}$ and low environmental temperature, respectively), while the significantly down-regulated TFs were mainly from the LOB and AP2 families (Figure 4c).
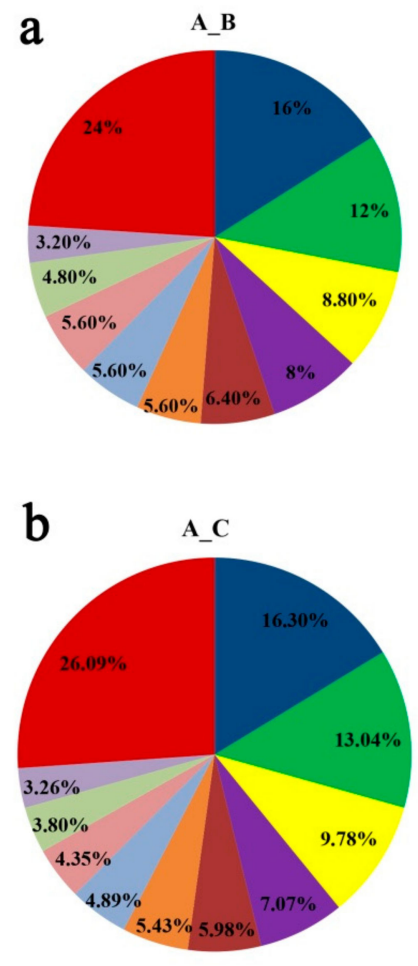

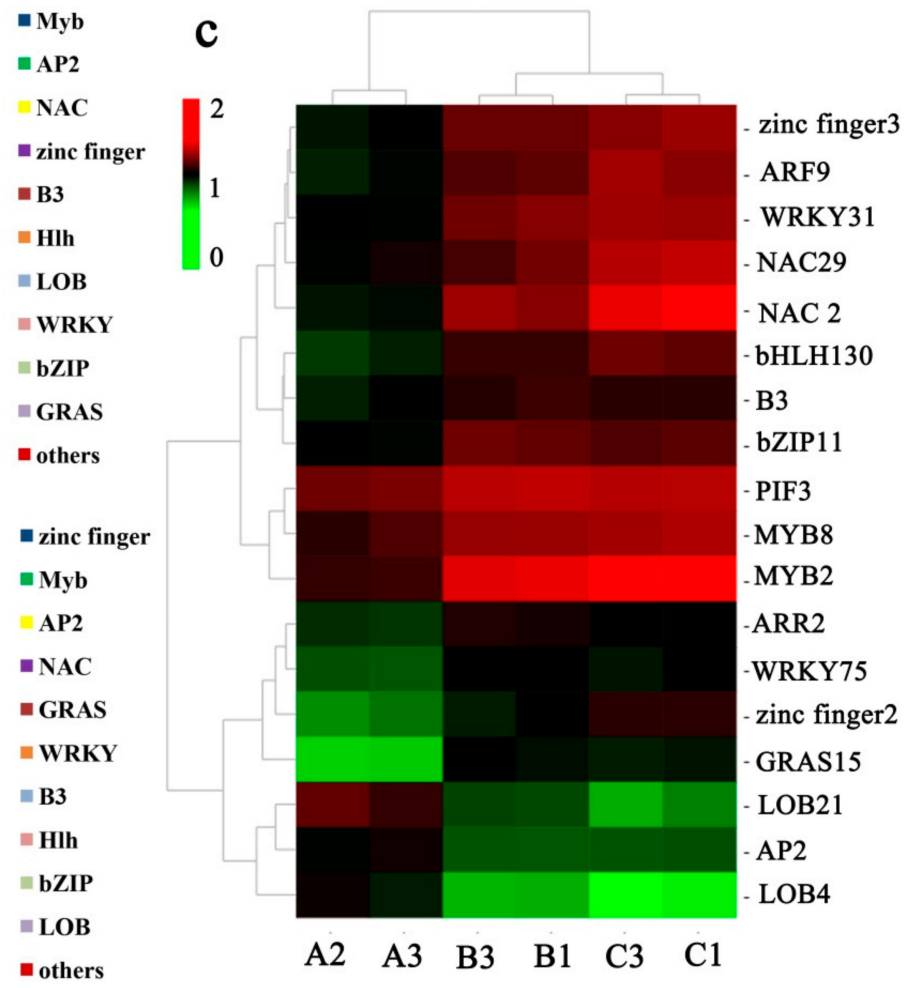

Figure 4. Analyses of the transcription factors (TFs) involved in Camellia oleifera 'Huaxin' response to low-temperature stress. (a) Distribution of transcription factor families in the A_B gene set; (b) Distribution of transcription factor families in the A_C gene set; (c) Expression profiles of 18 differentially expressed TFs among different samples. The heat map was generated from the log10 (FPKM values). Changes in expression level are represented by a change in color; green indicates a lower expression level, whereas red indicates a higher expression level. FPKM: fragments per kilobase of transcript per million mapped reads

A total of 90 and 117 DEGs encoding protein kinases were identified in the A_B and A_C gene sets, respectively. In the A_B gene set, there were 45 DEGs (22 up- and 23 down-regulated) encoding serine/threonine-protein kinase (STPK), including 10 DEGs of LRR receptor-like STPK, 9DEGs of CBL-interacting STPK, and 10 DEGs of G-type lectin S-receptor-like STPK. Besides, 
4DEGs ( 3 up- and 1 down-regulated) belonging to the CBL-interacting protein kinase (CIPK) family, 7DEGs (all down-regulated) encoding heat shock protein (Hsp70 protein), and 4 DEGs ( 2 up- and 2 down-regulated) of receptor-like kinase (RLKs) were identified. In theA_C gene sets, we found 68 DEGs (40 up- and 28 down-regulated) encoding STPK, including 16 DEGs of LRR receptor-like STPK, 10 DEGs of CBL-interacting STPK and 12 DEGs of G-type lectin S-receptor-like STPK. In addition, 5 DEGs (all up-regulated) belonging to the CIPK family, 5 DEGs (all up-regulated) belonging to the mitogen-activated protein kinase (MAPKs) family, 6 DEGs ( 5 up- and 1 down-regulated) belonging to the mitogen-activated protein kinase kinase kinase (MPKKK) family, and 21 DEGs (3 up- and 18 down-regulated) of RLKs were also identified in the A_C gene sets. Details on these PK genes are provided in Additional File 4.

\subsection{Hormone-Related DEGs Responding to Low Temperature}

A total of 26 DEGs in the A_B gene set and 40 DEGs in A_Cgene set were identified. These DEGs were involved in several plant hormone signal transduction pathways, including auxin, cytokinin (CK), gibberellin (GA), abscisic acid (ABA), and ethylene (ET), respectively. In the auxin signaling pathway, the transport inhibitor response 1 gene (TIR1) was down-regulated in the low temperature groups ( $\mathrm{B}$ and $\mathrm{C}$ ) compared with group $\mathrm{A}$, butthe auxin-responsive protein gene $(I A A)$ and the auxin-responsive GH3 gene (GH3) were down-regulated only in group B. In the CK pathway, the histidine-containing phosphotransfer protein gene $(A H P)$ was down-regulated, and the two-component response regulator genes belonging to the ARR-B or ARR-A family ( $A R R-B$ or $A R R-A)$ were up-regulated in the low-temperature groups (B and $C$ ) compared with group $A$. In the GA pathway, the gibberellin receptor GID1 gene (GID1) and the phytochrome-interacting factor 3 gene (PIF3) were up-regulated ingroups $\mathrm{B}$ and $\mathrm{C}$. In the $\mathrm{ABA}$ signaling pathway, the $\mathrm{ABA}$-responsive element binding factor gene $(A B F)$, the sucrose non-fermenting 1-related protein kinase 2 gene (SnRK2), and the protein phosphatase $2 \mathrm{C}$ gene $(P P 2 C)$ were up-regulated in group $\mathrm{B}$, while only the $A B F$ was up-regulated in group $C$ (Figure 5a). The heat map of the hormone-related DEGs showed that the genes T1R1, AHP, GH3, and $I A A$ were significantly down-regulated in the low-temperature groups (B and $\mathrm{C}$ ) compared with group A, while the genes GID1, SnRK2, PIF3, ARR-B, ARR-A, and PP2C were significantly up-regulated in groups B and C (Figure 5b). Details of these genes above are provided in Additional File 5: Table S5. The above results suggested that plant hormone signal transduction pathway played important roles in response to low-temperature stress in C. oleifera 'Huaxin'.

\subsection{Key DEGs Related to Photosynthesis}

The DEGs were significantly enriched in two KEGG pathways, i.e., 'Photosynthesis-antenna proteins' and 'Photosynthesis' (Figure 6a,b), with the encoding proteins mainly located in the chloroplast. Cluster analyses revealed that the expression levels of all these DEGs significantly differed among the three groups (A, B, C).The genes encoding PSII oxygen-evolving enhancer protein 1 (psbO), PSII oxygen-evolving enhancer protein 3 (psbQ), PSII $10 \mathrm{kDa}$ protein (psbR), PSII Psb27 protein (psb27), PSI subunit II (psaD), PSI subunit VI (psaH), PSI subunit PsaO (psaO), and F-type H+-transporting ATPase subunit delta $(\operatorname{atpH})$ were more highly expressed in group A $\left(25^{\circ} \mathrm{C}\right)$, but were significantly decreased in the low temperature groups (B and C) (Figure 6c, Additional File 6: Table S6). In addition, the expression levels of DEGs were consistent with the trends of photosynthetic physiological index such as Chl, $P_{n}$, ETR, and the starch content (Figure 1d-1f, 1h), indicating that these DEGs might relate to photosynthesis. However, only the expression levels of PSII $22 \mathrm{kDa}$ protein gene ( $p s b S$ ) were significantly increased in groups $\mathrm{B}$ and $\mathrm{C}$ compared with group $\mathrm{A}$, indicating that $p s b S$ may play an different role during long-term acclimation. 
a
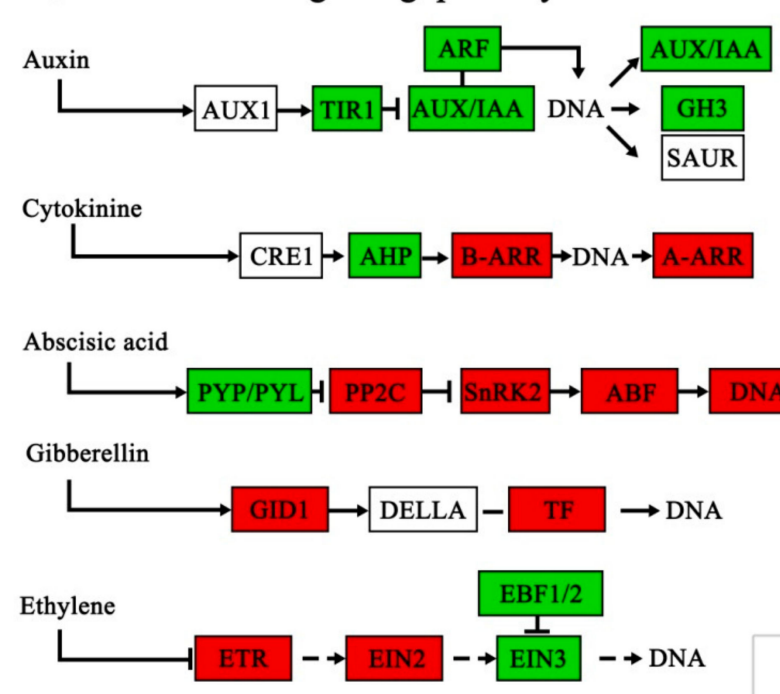

Brassinosteroid

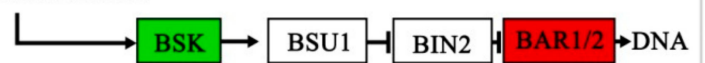

Jasmonic acid

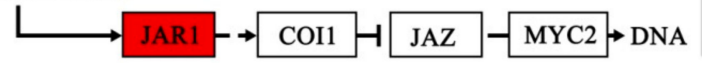

Salicylic acid

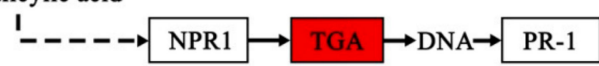

\section{b Expression patterns}

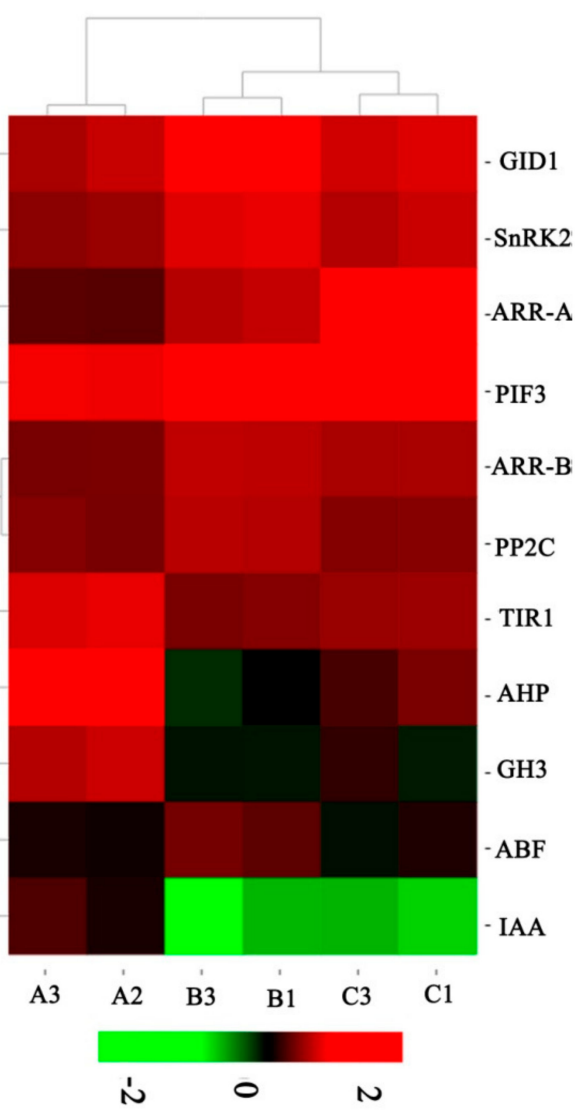

Figure 5. The differentially expressed genes in the hormone signaling pathways in response to low temperature in Camellia oleifera 'Huaxin'. (a) The green and red boxes show the mapped differentially expressed genes in the plant hormone signaling pathways, as modified from a Kyoto Encyclopedia of Genes and Genomes map (KO 04075), and the green boxes indicate down-regulated genes, whereas red boxes indicate up-regulated genes. (b) The expression patterns are shown as a heat map. Changes in expression level are indicated by a change in color, green indicates a lower expression level, whereas red indicates a higher expression level.

\subsection{Key DEGs Related to the Membrane System and Osmoregulation}

Low-temperature stress mainly damages the plasma membrane of plants. To sustain the functions of membrane proteins and lipids under cold stress, the plasma membrane needs to enhance lipid fluidity by increasing membrane lipids unsaturation levels [24], thus improving the cold tolerance of plants [25]. The current study identified five fatty acid desaturase (FAD) genes and three lipid-transfer protein (LTP) genes. Among them, four FADs were up-regulated in the group B $\left(6^{\circ} \mathrm{C}\right)$ and group $\mathrm{C}$ (low environmental temperature) while three LTPs were down-regulated compared to the group A $\left(25^{\circ} \mathrm{C}\right)$ (Additional File 7: Table S7). Previous studies [24,25] have shown that soluble sugars, including maltose, trehalose, raffinose and glucose, were increased to maintain osmotic balance under cold temperatures, thus maintaining the stability of the osmotic regulation systems. In this study, the expression of several genes in related metabolism pathways also changed with temperature. Two trehalose-6-phosphate synthase genes (TPSs), two $\beta$-amylase genes (AMY $\beta$ ), one $\alpha$-amylase gene $(A M Y \alpha)$, and one glucose-1-phosphate adenylyltransferase gene $(g \lg C)$ involved in the starch and sucrose metabolism pathway, and two raffinose synthase genes (RafS) involved in the galactose metabolism pathway were all up-regulated in the low temperature groups (B and C) (Additional File 7: Figure S2). These are the key genes involved in sugar metabolism, all of which were expressed at the highest levels in group $\mathrm{C}$ but at the lowest levels in group A. However, one hexokinase gene $(H K)$, 
three $\beta$-glucosidase genes $(\mathrm{bgl} \beta s)$ and two $\alpha$-galactosidase genes (gal $\alpha \mathrm{s})$ related to glucose synthesis were down-regulated in groups $B$ and $C$ compared with group $A$. The expression of these genes, which are related to glycometabolism, indicates that they respond differently to low temperatures.

\section{a PHOTOSYNTHESIS}

\begin{tabular}{|c|c|c|c|c|c|c|c|}
\hline \multicolumn{8}{|c|}{ Photosystem II } \\
\hline D1 & & $\mathrm{cp} 43$ & cp47 & \multicolumn{2}{|c|}{ cyt b559 } & \multirow[b]{3}{*}{ MSP } & \multirow[b]{3}{*}{$\mathrm{OEC}$} \\
\hline PsbA & PsbD & \begin{tabular}{|l|} 
PsbC \\
\end{tabular} & PsbB & PsbE & PsbF & & \\
\hline & & & & & & & \\
\hline PsbL & PsbJ & PsbK & PsbM & PsbH & PsbI & PsbO & PsbP \\
\hline$\overline{P s b Q}$ & PsbR & PsbS & PsbT & PsbU & PsbV & PsbW & PsbX \\
\hline PsbY & PsbZ & \begin{tabular}{|l|} 
Psb27 \\
\end{tabular} & Psb28 & Psb28-2 & & & \\
\hline Photosy & tem I & & & & & & \\
\hline PsbA & PsbB & \begin{tabular}{|l|} 
PsbC \\
\end{tabular} & PsbD & PsbE & PsbF & PsbG & $\mathrm{PsbH}$ \\
\hline PsbI & PsbJ & PsbK & PsbL & PsbM & PsbN & PsbO & PsbX \\
\hline F-type A & TPase & & & & & & \\
\hline beta & alpha & gamma & delta & epsilon & $\mathrm{c}$ & $\mathrm{a}$ & $\mathrm{b}$ \\
\hline
\end{tabular}

Light-harvesting chlorophyll protein complex(LHC) \begin{tabular}{|l|l|l|l|l|}
\hline Lhca1 & Lhca2 & Lhca3 & Lhca4 & Lhca5 \\
\hline
\end{tabular}

\begin{tabular}{|l|l|l|l|l|l|l|}
\hline Lhcb1 & Lhcb2 & Lhcb3 & Lhcb4 & Lhcb5 & Lhcb6 & Lhcb7 \\
\hline
\end{tabular}

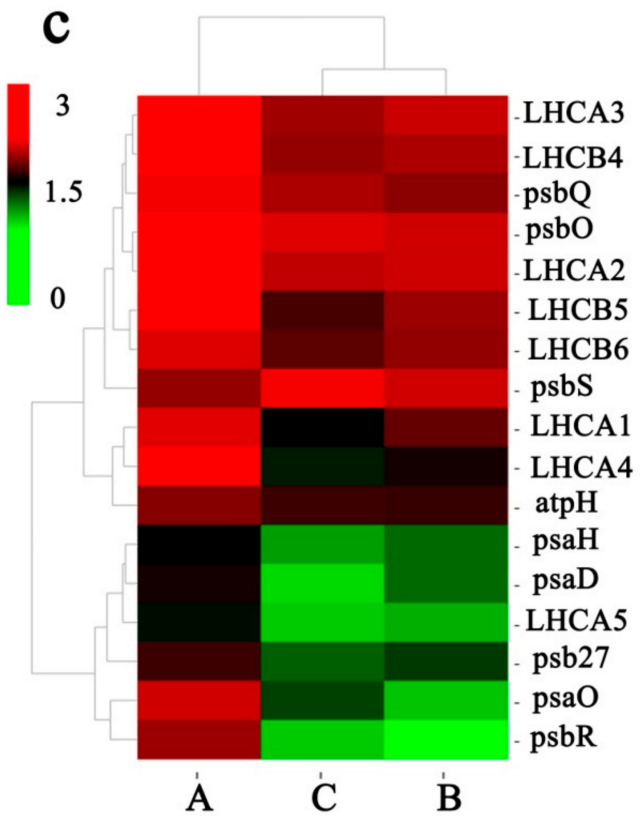

Figure 6. Differentially expressed genes (DEGs) related to photosynthesis pathways in response to low temperature in Camellia oleifera 'Huaxin'. (a) and (b) Green and red boxes show the mapped DEGs in the 'Photosynthesis' and 'Photosynthesis-antenna proteins' pathways, as modified from the KEGG maps (KO 00195 and KO 00196). (c) A comparison of the gene expression patterns. Changes in expression level are indicated by a change in color, green indicates a lower expression level, whereas red indicates a higher expression level.

\subsection{Other Important DEGs Responding to Low Temperature}

KEGG pathway analyses revealed several enriched pathways associated with DEGs in response to low temperature. The current study identified other important DEGs related to cold stress, including one 4-hydroxyphenylpyruvate dioxygenase gene $(H P D)$, two phenylalanine ammonia-lyase genes $(P A L S)$, and one cinnamate 4-hydroxylase gene $(C Y P 73 A)$ involved in phenylalanine metabolism pathway. In addition, three DEGs were identified involved in the flavonoid biosynthesis pathway, including flavonol synthase gene (FLS), flavonoid 3'-monooxygenase gene (CYP75B1), and chalcone synthase gene $(\mathrm{CHS})$, with significantly different expression in the three sample groups. The expression levels of $F L S, C Y P 75 B 1, H P D$, and CYP73A were significantly higher in the low temperature groups (B and $\mathrm{C}$ ) and lowest in the group $\mathrm{A}$ while the expression level of $\mathrm{CHS}$ was highest in the group $\mathrm{A}$ and lower in the low temperature groups (B and C) (Additional file 8: Table S8). In addition, the galactinol synthase genes (GOLSs) involved in the galactose metabolism pathway were all up-regulated in groups $\mathrm{B}$ and $\mathrm{C}$, while the gene of fatty acid hydroperoxide lyase (HPL) was significantly down-regulated. The expression of these genes changed in C. oleifera 'Huaxin' under low temperature, showing that these genes were induced by low-temperature stress.

\subsection{Quantitative RT-PCR Analysis}

To validate the reliability of the RNA-seq data, 12 target DEGs were selected and investigated by qRT-PCR. We compared the expression data of the 12 DEGs obtained by RNA-seqand qRT-PCR. The magnitude changes of these genes from three samples treated at different conditions observed by qRT-PCR were similar to that of RNA-seq (Figure 7), indicating that the RNA-seq data obtained in 
this study are reliable. However, differences in individual genes existed according to the RNA-seq and qRT-PCR results. For example, the expression levels of $a m y B$ (ID: c125403.graph_c2) and $p s b S$ (ID: c140493.graph_c0) were much higher in groups A and B when detected by qRT-PCR than as determined by RNA-seq, while the RPKM values of gene Rafs2 (ID: c139678.graph_c1) appeared much lower in groups A and C when detected by qRT-PCR than as determined by RNA-seq. The differences may be due to the facts that some primer pairs used in qRT-PCR were not optimal for detecting the target transcripts.

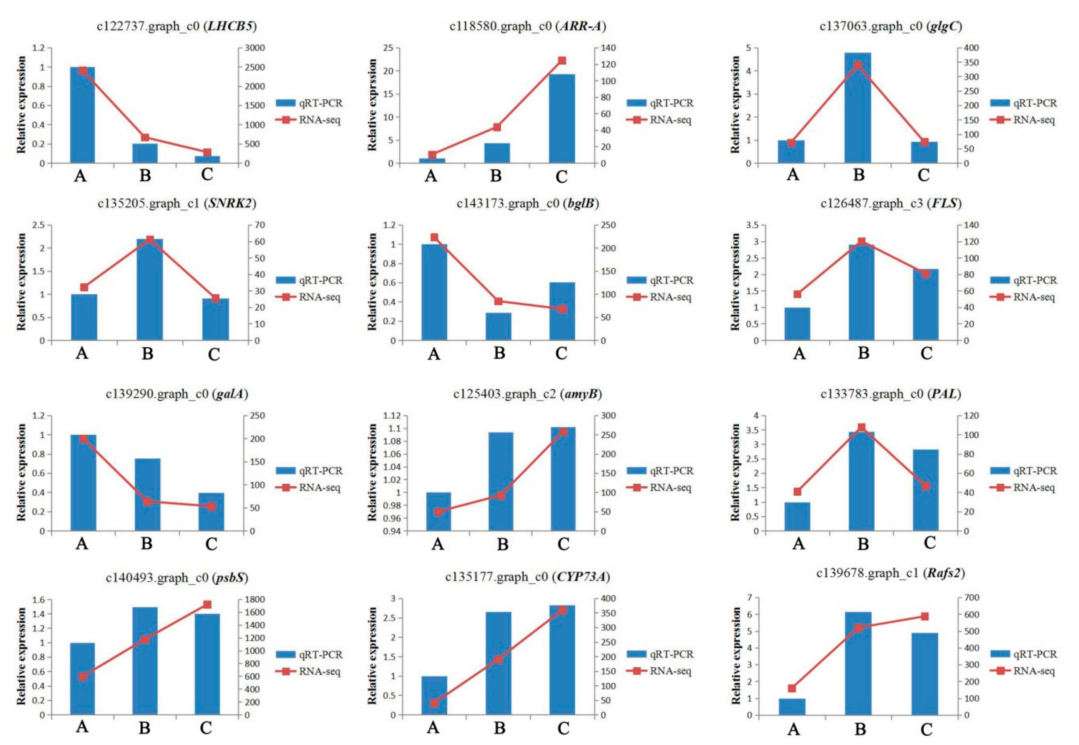

Figure 7. The comparison of the expression levels of 12 DEGs identified related to cold acclimation between RNA-Seq and qRT-PCR analyses from three samples treated at different temperatures.

\section{Discussion}

Tea-oil tree (Camellia oleifera) is an economically important trees pecies widely cultivated for edible oil production in China. C. oleifera is an evergreen tree species with a slow growth rate. It blossoms and yields fruits in the winter. Our previous study showed that low temperature had a great influence on the phenotype and physiology of C. oleifera 'Huaxin' leaves [19]. Normal flowering and fruiting require a lot of nutrients, which come from carbohydrate fixation by photosynthesis in the leaves. To better understand related genes expression of $C$. oleifera 'Huaxin' under low temperature stress, we performed transcriptomic analyses of leaves under long-term cold stress using Illumina NGS technology. The low growth rate of $C$. Oleifera 'Huaxin' results in only one main branch and no lateral branches at 2 years of age, while it can have 5-6 lateral branches at 4 years of age. Therefore, we chose 4 -year-old potted young plants as they generate plenty of experimental materials.

Temperature is an important factor that restricts plant geographical distribution and influences plant growth performance. Unfortunately, most species in the genus Camellia are sensitive to low temperatures, which makes them difficult to overwinter in cold regions [26]. Exploring the molecular and physiological mechanisms of cold resistance can contribute to the development of cold-resistant C. oleifera varieties. The current study conducted a systematic transcriptome profiling of cultivated C. oleifera 'Huaxin' under simulated cold stress and low environmental temperature. Several DEGs involved in cold-responsive processes were identified, including cold-related transcription factor and protein kinase genes, hormone-related genes, photosynthesis-related genes, membrane system and osmoregulation-related genes, and other important enzyme-related genes.

\subsection{Transcription Factors and Protein Kinase Responding to Low Temperature}

TFs are key factors involved in transmitting and amplifying low-temperature stress signals and regulating downstream resistance-related genes and their expression, thereby enhancing the cold 
tolerance of plants [27]. In this study, a large number of TF genes were involved in the low-temperature response. Generally, 11 families were identified with significant differential expression, including AP2, Myb, WRKY, bHLH, Hlh, zinc finger, B3, LOB, bZIP, GRAS, and NAC, most of which functioned as regulators related to cold stress responses [28]. The Myb and NAC families are generally considered the best-characterized classes of plant TFs, and many are involved in the cold response [29,30]. In this study, the Myb and NAC families were the two main groups that responded to cold stress, suggesting that $C$. oleifera 'Huaxin' might employ a complex mechanism of signaling and transcriptional reprogramming controlled by the Myb and NAC proteins. Moreover, the TF families were differentially expressed between simulated cold stress and low environmental temperature stress, which may have been due to the effects of other factors, such as light and moisture, or because the environmental temperature was much higher than the simulated temperature.

Plant protein kinases belong to a large super family, and some play a central role in signal perception and transmission in response to cold stress. For example, CIPK is a key kinase involved in the $\mathrm{Ca}^{2+}$-signaling pathway in response to cold stimuli [31]. The CIPKs, MAPKs, and MPKKKs are involved in phosphorylation and de-phosphorylation processes, which have key roles in conferring cold tolerance by increasing the cold signaling activities [32]. Previous studies showed that RLKs are involved in the perception of environmental signals [33]. In this study, all of the CIPK, MAPK, and MPKKK genes were up-regulated under low temperature treatments compared to normal temperature treatment, confirming that they positively regulated resistance to cold stress, while most of the RLK genes were down-regulated, indicating that their protein products negatively regulated C. oleifera 'Huaxin'. STPK enzyme functional activities are seen at the posttranslational level. Extensive STPK studies have been performed in pathogens, however, STPKs are implicated in the response to abiotic stress in higher plants [34,35]. Previously, Zorina [36] suggested that STPKs act as possible regulators of cold stress responses occurring at the transcriptional level in Synechocystis. In this study, genes mainly encoding three kinds of STPKs, including LRR receptor-like STPKs, CBL-interacting STPKs, and G-type lectin S-receptor-like STPKs were identified, and they were differentially expressed under low temperature stress; some were up-regulated and others were down-regulated compared to normal temperature. Because protein phosphorylation playsan important role in signal perception and transmission, these STPKs may participate in phosphorylation and de-phosphorylation processes that enable plants to survive in low-temperature environments. Therefore, these STPKs may act as cold stress sensors in the regulatory pathway of the cell response to cold stress.

\subsection{Hormone-Related DEGs Responding to Low Temperature}

Phytohormones are small-molecule chemicals that are involved in the regulation of plant growth and abiotic stress responses [37]. Hormone-related DEGs in pathways such as CK, GA, ABA, and ET participate in the synthesis and metabolism of plant hormones, and these hormones may amplify existing cascades or initiate new signaling pathways [38]. In this study, four key response hormone signal transduction pathways were identified in cold acclimation of C. oleifera 'Huaxin' including CK, GA, ABA, and ET. The CK signaling pathway is a two-component system consisting of AHKs, AHPs, and ARRs. Type-A ARR genes are rapidly induced by $\mathrm{CKs}$, and they regulate the activity of type-B ARRs via a negative feedback loop $[39,40]$. In this study, both $A R R-B$ and $A R R-A$ were up-regulated under low temperature stress, indicating that they might be key cold-responsive regulators that contribute to chilling tolerance. The ABA signaling pathway is a key regulator of the abiotic stress response in plants [41]. Low temperature can induce the expression of cold response genes (CORs), and ABA responds to cold stress by regulating these CORs. The expression of CORs depends on ABA-dependent and ABA-independent signaling pathways [28]. ABA-responsive element binding factor(ABF) can activate downstream gene expression in response to cold stress [42]. SnRK2 and PP2C are the main ABA receptors that form a signaling complex referred to as the "ABA signalosome". The ABA signalosome can turn on ABA signals by phosphorylation of downstream transcription factors, such as the AREB/ABF or membrane proteins involved in ion channels [43]. Here, $A B F, S n R K 2$, and 
PP2C were three key DEGs involving in ABA signal transduction pathway synthesis, all of which were up-regulated in response to low temperatures, suggesting that ABA biosynthesis and signaling components were important for the expression of cold-regulated genes(COR), and the expression of CORs in C. oleifera 'Huaxin' depends on ABA-dependent signaling pathway.

\subsection{Key DEGs Related to Photosynthesis}

The Lhc super-gene family is commonly divided into Lhca or Lhcb, depending on whether the gene products belong to the PSI or PSII super complexes, respectively. The Lhca super-gene family in green plants encodes several light-harvesting chlorophyll a/b-binding proteins, including Lhca1, Lhca2, Lhca3, Lhca4, and Lhca5, which harvest and transfer light energy to the reaction center of PSI in photosynthesis. The Lhcb super-gene family mainly encodes the heterotrimeric LHCII complex, including Lhcb1, Lhcb2, Lhcb3, Lhcb4, Lhcb5, Lhcb6, and Lhcb7, which are the most abundant membrane proteins on the Earth [44]. Low-temperature stress is necessary for photo-inhibition in chilling-sensitive plants such as pumpkin [45], maize [46], and sweetpepper [47]. In this study, photoinhibition was induced by long-term cold stress because $\mathrm{Chl}, \mathrm{ETR}$, and $P_{n}$ were significantly decreased under low temperatures compared to room temperature. Furthermore, the expression levels of Lhca and Lhcb genes significantly decreased under low temperatures, suggesting that low temperature may decrease the expression of $L h c a$ and $L h c b$ decreased, thus resulting in the decrease of Chl, ETR, and $P_{n}$ and the starch content. PSII is a multi-subunit pigment-protein complex in higher plants and is mainly distributed in the stacking area of thylakoids. It consists of three key proteins including exogenous subunit II proteins PsbO (33 kD), PsbP (23 kD), and PsbQ (17 kD), which are encoded by genes of PsbO, PsbP, and $P s b Q$, respectively. PsbR is a small subunit protein in PSII that has important roles in polymerization stability, photosynthetic protection, and water oxidation of PsbP and PsbQ [48]. PsbR expression was inaccordance with the trends of ETR and $P_{n}$ in C. oleifera 'Huaxin' in respond to cold stress, indicating that $P s b R$ may negatively regulate transcription during cold stress in C. oleifera 'Huaxin'. This was further supported by previous studies showing that down-regulation of $P s b R$ could lead to a decrease of $P_{n}$ and PSII photo energy conversion efficiency [49,50]. In addition, the reduced expression of $P s b R$ could lead to reduced activity of the core coding proteins, such as PsbO, PsbP, and PsbQ in PSII, thus affecting the cooperation between PSI and PSII, and blocking the metabolic pathway of photosynthesis in leaves, resulting in decreased $P_{n}$ and ETR. Rorat [51] found that chilling treatment of potatoes induced a strongly enhanced accumulation of the $p s b S$ transcripts. Interestingly, in this study, only the expression levels of $p s b S$ were significantly increased under low-temperature stress, indicating that the expression pattern of the $p s b S$ gene was different from other genes related to photosynthesis, and it might have positive transcription regulation in response to cold stress in C. oleifera 'Huaxin'.

\subsection{Key DEGs Related to the Membrane System and Osmoregulation}

FADs and LTPs not only participate in the formation of biofilm, keratin, and lipids but also play important roles in regulating the unsaturation levels of membrane lipids and mediate the regulation of membrane fluidity in response to cold stress [52]. As important defense proteins in plants, the expressions of genes encoding FAD and LTP are induced by stress factors such as drought, high salinity, and low temperature. The plasma membrane is a primary site of injury from cold stress in plants. When plants are subjected to low temperatures, FADs and LTPs act as regulatory proteins to stabilize plasma membrane activity and protect it from cold injury [53]. In this study, genes encoding FADs and LTPs in C. oleifera 'Huaxin' were much more active under low environmental temperature than those under simulated low temperature, indicating that the genes were better induced by low environmental temperature, and too low temperature was not conducive to the expression of FADs and LTPs genes.

Maltose can function as a compatible solute, stabilizing substances in the chloroplast stroma in response to low-temperature stress, and there is a connection between the accumulation of maltose and the expression of the $\beta$-amylase gene $(A M Y \beta)$, and low temperature can promote the hydrolysis of starch and increase the content of soluble sugar in cells [54]. Trehalose is a major osmotic protective 
substance present in organisms and some higher plants and can be accumulated in bacteria and yeasts in response to abiotic stresses [55]. Trehalose-6 monophosphate synthase (TPS) is the key enzyme synthesizing trehalose. In this study, the expressions of $A M Y \beta$ and TPS were increased under low temperatures, which accelerated the degradation of the starch and promoted the synthesis of soluble sugar and galactose. These results were consistent with the altered starch content, soluble sugar content and galactose content, indicating that $C$. oleifera 'Huaxin' achieved its cold tolerance by accumulating maltose and trehalose at the flowering stage. Furthermore, the accumulation of the raffinose family of oligosaccharides (RFOs) enhances cold resistance in angiosperms. Besides, inositol galactose and raffinose could act as osmotic protective substances for plants under cold stress [56]. Inositol galactoside is the precursor of RFO synthesis, which is catalyzed by inositol galactose synthase (GOLS). Raffinose is synthesized by transfer of the galactosyl groups from inositol galactoside to sucrose and raffinose, respectively, which are catalyzed by raffinose synthase (RafS). Therefore, GOLS and RafS are considered key enzymes in the biosynthesis of RFOs. In this study, the expression of GOLS and RafS was up-regulated under low-temperature stress, suggesting that these genes are positively regulated at the transcription level in response to cold stress through the accumulation of osmotic protective substances such as inositol, galactose and raffinose. These results are consistent with previous studies, in which the expression of GOLS increased in vegetative tissues in relation to frost-tolerance and transportation of RFOs in Ajugaretans when exposed to cold stress [57]. In summary, solutes such as maltose, trehalose, raffinose, and inositol galactose accumulated through cold-inducible gene expression, thus maintaining the stability of the osmotic regulation systems.

\subsection{Other Important DEGs Responding to Low Temperature}

CYP73A5 and CYP75B1 are two types of monooxygenase enzymes belonging to the cytochrome P450 superfamily. Recently, increasing evidence has shown that P450s confer abiotic stress tolerance in plants [58-60]. CYP73A5 and CYP75B1 encode enzymes that are associated with the synthesis of phenylpropanoid in Arabidopsis. Furthermore, the CYP73A5 and CYP75B1 proteins mediate various steps in phenylpropanoid synthesis [58]. The current study identified two CYP genes (CYP75B1 and CYP73A), which were up-regulated under low temperature stress. We assume that over expression of CYP75B1 and CYP73A might contribute to the cold resistance of C. oleifera 'Huaxin' by mediating the synthesis of phenylpropanoid. Flavonoids are other plant products that have multiple biological functions, and their accumulation usually occurs in plants when they are subjected to abiotic stresses [61]. Anthocyanins and flavonols are two of the most important flavonoids that accumulate in response to low temperatures [62,63]. CHS and FLS are two key flavonoid biosynthetic genes, which encode key regulatory enzymes that participate in anthocyanin synthesis [64,65]. Increased gene expression of $P A L$ and CHS might enhance cold tolerance in Fagopyrum tataricum and C. sinensis [22,66]. In addition, over accumulation of antioxidant flavonoids enhances ROS-scavenging activity under abiotic stresses $[67,68]$. In this study, the expression levels of CHS and FLS in C. oleifera 'Huaxin' were significantly increased under low temperatures, confirming that they enhanced cold tolerance in C. oleifera 'Huaxin' during cold acclimation.

\section{Materials and Methods}

\subsection{Plant Materials and Low-Temperature Treatments}

On February 18, 2016, 60 two-year-old C. oleifera cultivar 'Huaxin' (2009) young plants were selected and transplanted into plastic containers $(22 \times 22 \times 20 \mathrm{~cm})$ filled with a 2:1:1 mixture of peat soil, loess, and perlite. The plants were grown in field conditions with the same water and fertilizer management at the Life Science Building of Central South University of Forestry and Technology, Changsha, China $\left(28^{\circ} 10^{\prime} \mathrm{N}, 113^{\circ} 23^{\prime}\right.$ E). Two years later, on November 3, 2018, 54 four-year-old C. oleifera 'Huaxin' with similar growth rates were divided randomly into three groups. Each group consisted of 18 plants. Those three groups of $C$. oleifera 'Huaxin' potted plants were placed in three 
different temperatures for the experiments: normal temperature of $25^{\circ} \mathrm{C}$ in an artificial climate chamber as control (A); low temperature of $6{ }^{\circ} \mathrm{C}$ in an artificial climate chamber (B); and low environmental temperature in field conditions (C). Other parameters in each room of the artificial climate chamber $A$ and $\mathrm{B}$ were the same with $70 \%$ relative humidity, a 12 -h photoperiod at a photosynthetic photon flux density of $200 \mu \mathrm{mol} \cdot \mathrm{m}^{-2} \cdot \mathrm{s}^{-1}$, and an average $\mathrm{CO}_{2}$ concentration of $450 \mu \mathrm{mol} \cdot \mathrm{mol}^{-1}$ [19]. In the field condition $(\mathrm{C})$, the average air temperature wasapproximately $11.2{ }^{\circ} \mathrm{C}$, the average relative humidity was $82.6 \%$, and the average photosynthetically active radiation (PAR) was $360 \mu \mathrm{mol} \cdot \mathrm{m}^{-2} \cdot \mathrm{s}^{-1}$ on a cloudy day, and an average $\mathrm{CO}_{2}$ concentration of $392 \mu \mathrm{mol} \cdot \mathrm{mol}^{-1}$.

\subsection{Determination of Physiological Indexes of C. oleifera 'Huaxin' under Low Temperatures}

At 25 days after transplanting (25 DAT), the photosynthetic parameters, including $C h l, P_{n}$, and ETR, were measured following Gu et al. [11] using a Li-6400xt (LI-COR Biosciences, Lincoln, NE, USA). The parameters of the portable photosynthesis system were set with a PPFD source provided by LEDs (Light Emitting Diodes) emitting red-blue light at $1000 \mu \mathrm{mol} \cdot \mathrm{m}^{-2} \cdot \mathrm{s}^{-1}$. Meanwhile, the $\mathrm{CO}_{2}$ concentration was $400 \mu \mathrm{mol} \cdot \mathrm{mol}^{-1}$, and the flow rate was $500 \mu \mathrm{mol} \cdot \mathrm{s}^{-1}$. The contents of soluble sugar and starch were measured as described by Wang et al. [69]. The content of galactose was determined using ELISA kits in accordance with the manufacturer's instructions (Meimian industrial Co., Ltd., Jiangsu, China). The relative leaf water content (RWC) was determined according to the following equation: $\mathrm{RWC}=((\mathrm{FM}-\mathrm{DM}) /(\mathrm{SM}-\mathrm{DM})) \times 100 \%$. FM: leaves fresh mass; SM: leaves saturated mass; DM: leaves dry mass. The saturated mass was obtained after $24 \mathrm{~h}$ of leaf immersion in distilled water in the dark [70]. Nine seedlings for each treatment (three repetitions per treatment; three plants per replicate) and the leaves used for the measurements were kept under the same growth conditions and in similar growth positions.

\subsection{Sampling for RNA-Seq and RNA Preparation}

During 25 DAT the plants underwent different temperatures, intact mature leaves were selected for the physiological experiments and molecular sequencing analyses. For each treatment, three samples were selected, which were named A1, A2, A3, B1, B2, B3, C1, C2, and C3, respectively. Then the total nine samples were rapidly frozen in liquid nitrogen and stored at $-80{ }^{\circ} \mathrm{C}$. A total of nine samples were used for the RNA-Seq and differential expression analyses. To avoid gene expression differences among leaves from the respective plants, the RNAs from three leaves belonging to the same plant were grouped for transcriptome sequencing. The purity, concentration, and integrity of the RNA samples were tested using an agarose gel and the Nanodrop 2500 (Thermo Fisher Scientific, Waltham, MA, USA) to ensure that the samples were suitable for transcriptome sequencing [71].

\subsection{Library Preparation and RNA Sequencing}

RNA samples were sent to Beijing Baimeike Biotechnology Co., Ltd. (Shunyi District, Beijing, China), where the libraries were produced and sequenced. For sample preparation, $1 \mu \mathrm{g}$ RNA per sample was used. Sequencing libraries were generated according to the instructions in the NEBNext ${ }^{\circledR}$ Ultra $^{\text {TM }}$ RNA Library Prep Kit for Illumina ${ }^{\circledR}$ (NEB, San Diego, CA, USA), and index codes were added to attribute sequences to each sample. Briefly, mRNA was purified from total RNA using poly $\mathrm{T}$ oligo-attached magnetic beads. Fragmentation was carried out using divalent cations under elevated temperature in NEB Next First Strand Synthesis Reaction Buffer (5X). First-strand cDNA was synthesized using random hexamer primers and M-MuLV Reverse Transcriptase. Second-strand cDNA synthesis was subsequently performed using DNA polymerase I and RNase $\mathrm{H}$. Any remaining overhangs were converted into blunt ends using exonuclease/polymerase. After adenylation of the $3^{\prime}$ ends of the DNA fragments, the NEBNext Adaptor with a hairpin loop structure was ligated to prepare the DNA for hybridization. To select cDNA fragments of $\sim 240 \mathrm{bp}$ in length, the library fragments were purified with AMPure XP (Beckman Coulter, Beverly, MA, USA). Next, $3 \mu \mathrm{L}$ of USER Enzyme (NEB) were used with size-selected, adaptor-ligated cDNA at $37^{\circ} \mathrm{C}$ for $15 \mathrm{~min}$, followed by $5 \mathrm{~min}$ at $95^{\circ} \mathrm{C}$ 
before the PCR. Then PCR was performed with Phusion High-Fidelity DNA polymerase, Universal PCR primers, and Index $(X)$ Primer. The PCR products were purified (AMPure XP), and the library quality was assessed using an Agilent Bioanalyzer 2100.

\subsection{Transcriptome Assembly and Gene Functional Annotation}

The left files (read1 files) from all libraries/samples were pooled into one big left.fq file and the right files (read2 files) were pooled into one big right.fq file. Transcriptome assembly was accomplished based on the left.fq and right.fq using Trinity [72] with min_kmer_cov set to 2 by default and all other parameters set to default. Gene function was annotated based on the following databases: NR, Pfam, KOG, COG, eggNOG, Swiss-Prot, KEGG, and GO.

\subsection{Differential Expression Analyses}

Gene expression levels were estimated by RSEM [73] for each sample, in which fragments per kilobase of transcript per million mapped reads (FPKM) were used to estimate gene expression levels. Differential expression analyses of two sample groups at different temperature conditions were performed using the DESeq2 [74]. DESeq2 provides statistical routines for determining differential expression in digital gene expression data using a model based on the negative binomial distribution. The Benjamin Hochberg method was used to correct the significance $p$-value obtained from the original hypothesis test, and finally the corrected $p$-value (FDR, false discovery rate) was used as the key indicator of screening differential expression gene. In this study, the FDR $<0.01$ and FC (fold change) $\geq 2$ were set as the screening indexes for significantly differentially expressed genes. The differential expression gene set was obtained through analyzing the differential expression between two samples groups, and the gene sets were named A_B, B_C and A_C in the analysis results.

\subsection{Quantitative Real-Time PCR (qRT-PCR) Analysis}

To validate the accuracy of the RNA-seq results, a total of 12 DEGs related to cold acclimation were selected for qRT-PCR validation, and the ACTIN11 (Glyma.18g290800) was used as the housekeeping gene. The total RNA was extracted from the same plant used for RNA sequencing. Three biological replicates were carried out for each treatment with three technological replications for each gene. The cDNA was synthesized from 500ng total RNA in a $20-\mu \mathrm{L}$ reaction system by Aidlab reverse transcription Kit (TUREscript 1st Stand cDNA SYNTHESIS Kit). The specific primers were designed based on Primer Premier 5.0 (Additional file 9: Table S9). Quantitative RT-PCR was performed using Analytikjena-Qtower 2.2 (Jena, Germany) in a final qRT-PCR reaction mixture containing 5.0 $\mu \mathrm{L} 2 \times \mathrm{SYBR}^{\circledR}$ Green Supermix, $1.0 \mathrm{uL}$ primers, $1.0 \mu \mathrm{L}$ cDNA, and $3.0 \mu \mathrm{L} \mathrm{ddH}_{2} \mathrm{O}$. The calculation of the relative expression of the target gene in each sample was conducted using the $2^{-\Delta \Delta C t}$ method as described previously [75]. The relative expression values of qPCR and RPKM values of RNA-seq were compared.

\subsection{Statistical Analyses}

All data were conducted with three replicates, and the results presented are the mean values. Microsoft Office Excel 2013 was used to process the data. The data of photosynthetic physiology were subjected to a one-way analysis of variance (ANOVA) with SPSS 17.0 software using Duncan's multiple range test at the 0.05 level of significance. Other analyses of significance are illustrated in the corresponding section of the relevant method introduction.

\section{Conclusions}

The current study presents a transcriptome profile of cultivated C. oleifera 'Huaxin' using Illumina NGS technology to combine physiological data, which contributes to the understanding of the underlying transcriptional response mechanism of C. oleifera 'Huaxin' to low temperatures. Large 
numbers of DEGs in C. oleifera 'Huaxin' are induced by long-term cold stress, leading to phenotypic differences. The current study explored a series of potential chilling-resistant genes associated with photosynthesis, signal transduction, biofilm systems, and osmotic regulation systems, which can serve as candidate genes for cold tolerance in molecular breeding programs of C. oleifera 'Huaxin'. Long-term cold stress could trigger the establishment of cold-resistance mechanisms and ultimately improve the adaptability of $C$. oleifera 'Huaxin' to cold stress.

Supplementary Materials: Supplementary materials can be found at http://www.mdpi.com/1422-0067/21/3/846/s1.

Author Contributions: X.T. and J.L. formulated and designed the experiments; L.W. performed the experiments, analyzed the data, and wrote the paper; Z.L. and F.Z. cultivated Camellia oleifera 'Huaxin' plants and revised the paper. All authors have read and agreed to the published version of the manuscript.

Funding: This work was supported by the Major Projects of Science and Technology Project of Hunan Province (grant number 2018NK1030), the Hunan Postgraduate Science and Technology Innovation Project (grant number CX2018B438), and the Central South University of Forestry and Technology Postgraduate Science and Technology Innovation Fund Project (grant number 20181004).

Acknowledgments: The English in this document has been checked by at least two professional editors, both native speakers of English. For a certificate, please see: http://www.textcheck.com/certificate/CiKIWI.

Conflicts of Interest: The authors declare that they have no conflict of interest.

\section{References}

1. Tan, X.F.; Jiang, G.X.; Tan, F.Y. Research report on industrialization development strategy of Vernicia fordii in China. Non Wood Forest Res. 2011, 29, 1-5.

2. Li, Z.; Tan, X.F.; Liu, Z.M.; Lin, Q.; Zhang, L.; Yuan, J.; Zeng, Y.L.; Wu, L.L. In vitro propagation of Camellia oleifera abel. using hypocotyl, cotyledonary node, and radicle explants. Hort Sci. 2016, 51, 416-421. [CrossRef]

3. Qu, X.J.; Wang, H.; Chen, M.; Liao, J.; Yuan, J.; Niu, G.H. Drought stress-induced physiological and metabolic changes in leaves of two oil tea cultivars. J. Amer. Soc. Hort. 2019, 144, 1-9. [CrossRef]

4. Gao, C.; Yuan, D.Y.; Yang, Y.; Wang, B.F.; Liu, D.M.; Zou, F. Pollen tube growth and double fertilization in Camellia oleifera. J. Amer. Soc. Hort. 2015, 140, 12-18. [CrossRef]

5. Chen, J.M.; Yang, X.Q.; Huang, X.M.; Duan, S.H.; Long, C.; Chen, J.K.; Rong, J. Leaf transcriptome analysis of a subtropical evergreen broadleaf plant, wild oil-tea camellia (Camellia oleifera), revealing candidate genes for cold acclimation. BMC Genom. 2017, 18, 211-216. [CrossRef] [PubMed]

6. Qin, S.Y.; Rong, J.; Zhang, W.J.; Chen, J.K. Cultivation history of Camellia oleifera and genetic resources in the Yangtze River Basin. Biodivers. Sci. 2018, 26, 384-395. [CrossRef]

7. Jiang, Y.H.; Liao, Y.F. Research summary on meteorological influence indicators of oil tea Camellia. Chin. Agric. Sci. Bull. 2015, 31, 179-183.

8. Andreas, T.; Christophe, C.; Essaï, A.B. Physiological and molecular changes in plants grown at low temperatures. Planta 2012, 235, 1091-1105.

9. Wu, Z.J; Li, X.H.; Liu, Z.W.; Li, H.; Wang, Y.X.; Zhuang, J. Transcriptome-based discovery of AP2/ERF transcription factors related to temperature stress in tea plant (Camellia sinensis). Funct. Integr. Genomic. 2015, 15, 741-752. [CrossRef]

10. Zeng, Y.R.; Ni, Z.J. Effects of the climate during flowering period on post-flowering fruit setting in Camellia oleifera. J. Zhejiang For. Coll. 2010, 27, 323-328.

11. Gu, Y.Y.; Zhang, F.H.; Zeng, Y.L.; Zhang, L.; Tan, X.F.; Cao, H.P.; Li, Z. Physiological responses of tung tree (Vernicia fordii) saplings to different red, white and blue light-emitting diodes. Intl. J. Agric. Biol. 2019, 22, 569-577.

12. Knight, M.R.; Knight, H. Low temperature perception leading to gene expression and cold tolerance in higher plants. New Phytol. 2012, 195, 737-751. [CrossRef] [PubMed]

13. Miura, K.; Furumoto, T. Cold signaling and cold response in plants. Int. J. Mol. Sci. 2013, 14, 5312-5337. [CrossRef]

14. Shibasaki, K.; Uemura, M.; Tsurumi, S.; Rahman, A. Auxin response in Arabidopsis under cold stress: underlying molecular mechanisms. Plant Cell 2009, 21, 3823-3838. [CrossRef] 
15. Mahajan, S.; Tuteja, N. Cold, salinity and drought stresses: An overview. Arch. Biochem. Biophys. 2005, 444, 0-158. [CrossRef] [PubMed]

16. Zhou, S.X.; Liu, L.F.; Wang, P.; Zhu, H.J. The features of the climate adaptability about Camellia oleifera planting in hilly red soil region of southern China: a case study of Changning City Hunan Province. Ecol. Sci. 2015, 34, 61-67.

17. Tan, X.F.; Yuan, D.Y.; Zou, F.; Yuan, J.; Xie, P.; Su, Y.; Wang, Y.; Yang, D.T.; Peng, J.T. An Elite Variety: Camellia oleifera 'Huaxin'. Sci. Silvae Sin. 2012, 48, 170-174.

18. Peng, S.F.; Chen, Y.Z. Freezing injury to oil-tea Camellia and measures to its prevention and remedy. Sci. Silv. Sin. 2008, 24, 184-188.

19. Wu, L.L.; Li, J.A.; Gu, Y.Y.; Zhang, F.H.; Gu, L.; Tan, X.F.; Shi, M.W. Effect of chilling temperature on florescence, leaf anatomical structure, and physiological and biochemical characteristics of two Camellia oleifera cultivars. Intl. J. Agric. Biol.. accepted.

20. Wang, X.C.; Zhao, Q.Y.; Ma, C.L.; Zhang, Z.H.; Yang, Y.J. Global transcriptome profiles of Camellia sinensis during cold acclimation. BMC Genom. 2013, 14, 415-429. [CrossRef]

21. Wu, Z.J.; Li, X.H.; Liu, Z.W.; Xu, Z.S.; Zhuang, J. De novo assembly and transcriptome characterization: novel insights into catechins biosynthesis in Camellia sinensis. Bmc Plant Biol. 2014, 14, 227-240. [CrossRef] [PubMed]

22. Li, Y.Y.; Wang, X.W.; Ban, Q.Y.; Zhu, X.X.; Jiang, C.J.; Wei, C.L.; Jeffrey, L.B. Comparative transcriptomic analysis reveals gene expression associated with cold adaptation in the tea plant Camellia sinensis. BMC Genom. 2019, 20, 624-641. [CrossRef] [PubMed]

23. Xia, E.H.; Jiang, J.J.; Huang, H.; Zhang, L.P.; Zhang, H.B.; Gu, L.Z. Transcriptome Analysis of the Oil-Rich Tea Plant, Camellia oleifera, Reveals Candidate Genes Related to Lipid Metabolism. PloS ONE 2014, 9, e104150. [CrossRef] [PubMed]

24. Zhou, Z.; Wang, M.J.; Zhao, S.T.; Hu, J.J.; Lu, M.Z. Changes in freezing tolerance in hybrid poplar caused by up- and down-regulation of PtFAD2 gene expression. Transgenic Res. 2010, 19, 647-654. [CrossRef] [PubMed]

25. Li, B.; Takahashi, D.; Kawamura, Y.; Uemura, M. Comparison of plasma membrane proteomic changes of Arabidopsis suspension-cultured cells (T87 line) after cold and ABA treatment in association with freezing tolerance development. Plant Cell Physiol. 2012, 53, 543-554. [CrossRef]

26. Aiello, A.S. Seeking Cold-Hardy Camellias. Arnoldia 2009, 67, 20-30.

27. Kasuga, M.; Liu, Q.; Miura, S.; Yamaguchi-Shinozaki, K.; Shinozaki, K. Improving plant drought, salt, and freezing tolerance by gene transfer of a single stress-inducible transcription factor. Nat. Biotechnol. 1999, 17, 287-291. [CrossRef]

28. Buskirk, H.A.; Thomashow, M.F. Arabidopsis transcription factors regulating cold acclimation. Physiol. Plant. 2006, 126, 72-80. [CrossRef]

29. Cominelli, E.; Gusmaroli, G.; Conti, L.; Allegra, D.; Petroni, K.; Tonelli, C. Role of Arabidopsis MYB transcription factors in osmotic stress. Plant Toler. Abiotic Stresses Agric. Role Genet. Eng. 2000. [CrossRef]

30. Ma, J.; Wang, F.; Li, M.Y.; Jiang, Q.; Tan, G.F.; Xiong, A.S. Genome wide analysis of the NAC transcription factor family in Chinese cabbage to elucidate responses to temperature stress. Sci. Hortic. 2014, 165, 82-90. [CrossRef]

31. Cheong, Y.H.; Kim, K.N.; Pandey, G.K.; Gupta, R.; Grant, J.J.; Luan, S. CBL1, a calcium sensor that differentially regulates salt, drought and cold responses in Arabidopsis. Plant Cell 2003, 15, 1833-1845. [CrossRef] [PubMed]

32. Denu, J.M.; Stuckey, J.A.; Saper, M.A.; Dixon, J.E. Form and function in protein dephosphorylation. Cell 1996, 87, 361-364. [CrossRef]

33. Lehti-Shiu, M.D.; Zou, C.; Hanada, K.; Shiu, S.H. Evolutionary history and stress regulation of plant receptor-like kinase/pelle genes. Plant Physiol. 2009, 150, 12-26. [CrossRef] [PubMed]

34. Los, D.A.; Zorina, A.A.; Sinetova, M.; Kryazhov, S.; Mironov, K.; Zinchenko, V.V. Stress sensors and signal transducers in Cyanobacteria. Sensors 2010, 10, 2386-2415. [CrossRef]

35. Zorina, A.A. Eukaryotic protein kinases in Cyanobacteria. Russ. J. Plant Physiol. 2013, 60, 589-596. [CrossRef]

36. Zorina, A.A.; Bedbenov, V.S.; Novikova, G.V.; Panichkin, V.B.; Los, D.A. Involvement of serine/threonine protein kinases in the cold stress response in the Cyanobacteriumsynechocystissp. pcc 6803: functional characterization of SpkE protein kinase. Mol. Biol. 2014, 48, 390-398. [CrossRef]

37. Peleg, Z.; Blumwald, E. Hormone balance and abiotic stress tolerance in crop plants. Curr. Opin. Plant Biol. 2011, 14, 290-295. [CrossRef] 
38. Yadav, S.K. Cold stress tolerance mechanisms in plants. In Sustainable Agriculture Volume 2; Springer: Dordrecht, The Netherlands, 2011.

39. Muller, B.; Sheen, J. Advances in cytokinin signaling. Science 2007, 318, 68-69. [CrossRef]

40. Ha, S.; Vankova, R.; Yamaguchi-Shinozaki, K.; Shinozaki, K.; Tran, L.S. Cytokinins: metabolism and function in plant adaptation to environmental stresses. Trends Plant Sci. 2012, 17, 172-179. [CrossRef]

41. Danquah, A.; De Zelicourt, J.; Colcombet,, A.; Hirt, H. The role of ABA and MAPK signaling pathways in plant abiotic stress responses. Biotechnol. Adv. 2014, 32, 40-52. [CrossRef]

42. Sijmons, P.C.; Grundler, F.M.W.; Mende, N.; Burrows, P.R.; Wyss, U. Arabidopsis thaliana as a new model for plant-parasitic nematodes. Plant J. 1991, 1, 245-254. [CrossRef]

43. Toledo-Ortiz, G.; Huq, E.; Quail, P.H. The Arabidopsis basic/helix-loop-helix transcription factor family. Plant Cell 2003, 15, 1749-1770. [CrossRef] [PubMed]

44. Caffarri, S.; Frigerio, S.; Olivieri, E.; Righetti, P.G.; Bassi, R. Differential accumulation of lhcb gene products in thylakoid membranes of Zea mays plants grown under contrasting light and temperature conditions. Proteomics 2005, 5.

45. Barth, C.; Krause, G.H. Inhibition of photosystem I and II in chilling-sensitive and chilling-tolerant plants under light and low temperature stress. Naturforsch 1999, 54, 645-657. [CrossRef]

46. Gabriella, S.; Majláth, I.; Pál, M.; Gondor, O.K.; Rudnóy, S.; Oláh, C. Janus-faced nature of light in the cold acclimation processes of Maize. Front. Plant Sci. 2018, 9, 850.

47. Li, X.G.; Meng, Q.W.; Jiang, G.Q.; Zou, Q. The susceptibility of cucumber and sweet pepper to chilling under low irradiance is related to energy dissipation and water-water cycle. Photosynthetica 2003, 41, 259-265. [CrossRef]

48. Nield, J.; Barber, J. Refinement of the structural model for the Photosystem II super complex of higher plants. Biochim. Biophys. Acta (BBA)-Bioenerg. 2006, 1757, 353-361. [CrossRef]

49. Xu, Y.Z.; Zeng, X.C.; Sun, W.C.; Wu, J.Y.; Fang, Y.; Liu, Z.G.; Ma, L. Cloning of PsbR gene in winter turnip rape (Brassica campestris) and its expression analysis under low temperature stress. J. Agricultural Biotechnol. 2017, 25, 1423-1433.

50. Cui, C.; Wang, L.J.; Zhou, Q.Y.; Tan, Z.F.; Qu, C.M.; Zhang, Z.S. Expression profiling of genes related to photosynthesis and antioxidant capacity in flue-cured tobacco seedlings subjected to chilling stress. Acta Ecol. Sin. 2014, 34, 6076-6089.

51. Rorat, T.; Havaux, M.; Irzykowski, W.; Stéphan, C.; Noëlle, B.; Rey, P. PSII-S gene expression, photosynthetic activity and abundance of plastid thioredoxin-related and lipid-associated proteins during chilling stress in solanum species differing in freezing resistance. Physiol. Plant. 2001, 113, 72-78. [CrossRef]

52. Wang, K.; Bai, Z.Y.; Liang, Q.Y.; Liu, Q.L.; Zhang, L.; Pan, Y.Z.; Liu, G.L.; Jiang, B.B.; Zhang, F.; Jia, Y. Transcriptome analysis of Chrysanthemum (Dendranthemagrandiflorum) in response to low temperature stress. BMC Genom. 2018, 19, 319-333. [CrossRef] [PubMed]

53. Hincha, D.K. Cryoprotectin: a plant lipid-transfer protein homologue that stabilizes membranes during freezing. Philos. Trans. R. Soc. B Biol. Sci. 2002, 357, 909-916. [CrossRef] [PubMed]

54. Kaplan, F.; Guy, C.L. $\beta$-amylase induction and the protective role of maltose during temperature shock. Plant Physiol. 2004, 135, 1674-1684. [CrossRef] [PubMed]

55. Tordachescu, M.; Imai, R. Trehalose Biosynthesis in Response to Abiotic Stresses. J. Integr. Plant Biol. 2010, 50, 1223-1229. [CrossRef]

56. Konrádová, H.; Gricová, M.; Lipavská, H. Cold-induced accumulation of raffinose family oligosaccharides in somatic embryos of norway spruce (Piceaabies). In Vitro Cell. Dev. Biol.-Plant. 2003, 39, 425-427.

57. Sprenger, N.; Keller, F. Allocation of raffinose family oligosaccharides to transport and storage pools in Ajugareptans: the roles of two distinct galactinol synthases. Plant J. 2010, 21, 249-258. [CrossRef]

58. Arti, R.; Ruchi, S.; Arvind, S.P.; Deo, T.R.; Kumar, T.P.; Debasis, C. Expression of rice cyp450-like gene (os08g01480) in Arabidopsis modulates regulatory network leading to heavy metal and other abiotic stress tolerance. PloS ONE 2015, 10, e0138574.

59. Tamiru, M.; Undan, J.R.; Takagi, H.; Abe, A.; Yoshida, K.; Undan, J.Q.; Natsume, S.; Uemura, A.; Saitoh, H.; Matsumura, H.; et al. A cytochrome P450 (OsDSS1) is involved in growth and drought stress responses in rice (Oryzasatival.). Plant Mol. Biol. 2015, 88, 85-99. [CrossRef] 
60. Wang, C.; Yang, Y.; Wang, H.; Ran, X.; Li, B.; Zhang, J.; Zhang, H. Ectopic expression of a cytochrome P450 monooxygenase gene PtCYP714A3 from Populustrichocarpa reduces shoot growth and improves tolerance to salt stress in transgenic rice. Plant Biotechnol. J. 2016, 14, 1838-1851. [CrossRef]

61. Singh, B.; Kumar, A.; Malik, A.K. Flavonoids biosynthesis in plants and its further analysis by capillary electrophoresis. Electrophoresis 2017, 38, 820-832. [CrossRef]

62. Taulavuori, E.; Tahkokorpi, M.; Taulavuori, K.; Laine, K. Anthocyanins and glutathione S-transferase activities in response to low temperature and frost hardening in Vacciniummyrtillus (L.). J. Plant Physiol. 2004, 161, 903-911. [CrossRef] [PubMed]

63. Gondor, O.K.; Szalai, G.; Kovács, V.; Janda, T.; Pál, M. Relationship between polyamines and other cold-induced response mechanisms in different cereal species. J. Agro. Crop. Sci. 2016, 202, 217-230. [CrossRef]

64. Leyva, A. Low temperature induces the accumulation of phenylalanine ammonia-lyase and chalcone synthase mRNAs of Arabidopsis thaliana in a light-dependent manner. Plant Physiol. 1995, 108. [CrossRef]

65. Schulz, E.; Tohge, T.; Zuther, E.; Fernie, A.R.; Hincha, D.K. Natural variation in flavonol and anthocyanin metabolism during cold acclimation in Arabidopsis thaliana accessions. Plant Cell Environ. 2015, 38, 1658-1672. [CrossRef] [PubMed]

66. Zhang, X.W.; Li, C.; Jiang, Q.T.; Wei, Y.; Yao, H.; Chen, H.; Wu, Q. Cloning and characterization of a cold inducible Pal promoter from Fagopyrumtataricum. Cent. Eur. J. Biol. 2014, 9, 290-297.

67. Nakabayashi, R.; Yonekura-Sakakibara, K.; Urano, K.; Suzuki, M.; Yamada, Y.; Nishizawa, T.; Matsuda, F.; Kojima, M.; Sakakibara, H.; Shinozaki, K.; et al. Enhancement of oxidative and drought tolerance in Arabidopsis by over accumulation of antioxidant flavonoids. Plant J. 2014, 77, 367-379. [CrossRef]

68. Watanabe, M.; Ayugase, J. Effect of low temperature on flavonoids, oxygen radical absorbance capacity values and major components of winter sweet spinach (Spinaciaoleracea, L.). J. Sci. Food. Agric. 2015, 95, 2095-2104. [CrossRef]

69. Wang, B.M.; Chen, J.; Chen, L.; Wang, X.; Wang, R.; Ma, L.; Peng, S.; Luo, J.; Chen, Y. Combined drought and heat stress in Camellia oleifera cultivars: leaf characteristics, soluble sugar and protein contents, and Rubisco gene expression. Trees 2015, 29, 1483-1492. [CrossRef]

70. Li, Z.; Tan, X.F.; Lu, K.; Liu, Z.M.; Wu, L.L. The effect of $\mathrm{CaCl}_{2}$ on calcium content, photosynthesis, and chlorophyll fluorescence of tung tree seedlings under drought conditions. Photosynthetica 2017, 55, 553-560. [CrossRef]

71. Li, W.; Xiang, F.; Zhong, M.; Zhou, L.; Liu, H.; Li, S.; Wang, X. Transcriptome andmetabolite analysis identifies nitrogen utilization genes in tea plant (Camellia sinensis). Sci. Rep. 2017, 7, 1693. [CrossRef]

72. Grabherr, M.G.; Haas, B.J.; Yassour, M.; Levin, J.Z.; Thompson, D.A.; Amit, I.; Adiconis, X.; Fan, L.; Raychowdhury, R.; Zeng, Q.; et al. Full-length transcriptome assembly from RNA-Seq data without a reference genome. Nat. Biotechnol. 2011, 29, 644-652. [CrossRef]

73. Dewey, C.N.; Bo, L. RSEM: accurate transcript quantification from RNA-Seq data with or without a reference genome. BMC Bioinform. 2011, 12, 323.

74. Anders, S.; Huber, W. Differential expression analysis for sequence count data. Genome Biol. 2010, 11, $106-112$. [CrossRef] [PubMed]

75. Schmittgen, T.D.; Livak, K.J. Analyzing real-time PCR data by the comparative CT method. Nat. Protoc. 2008, 3, 1101-1108. [CrossRef] [PubMed]

(C) 2020 by the authors. Licensee MDPI, Basel, Switzerland. This article is an open access article distributed under the terms and conditions of the Creative Commons Attribution (CC BY) license (http://creativecommons.org/licenses/by/4.0/). 